\title{
Lettlands Bedeutung
}

\section{für die östliche Frage}

Von

\section{H. F. Crohn-Wolfgang}

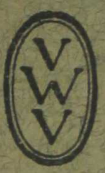

Berlin und Leipzig 1923

Walter de Gruyter \& Co.

vormals G. J. Gobschen'sche Verlagshandlung - J. Guttentag, Verlagsbuchhandlung

Georg Reimer - Karl J. Trübner - Veit \& Comp. 


\title{
Lettlands Bedeutung
}

\section{für die östliche Frage}

\author{
Von
}

H. F. Crohn-Wolfgang

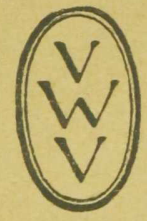

Berlin und Leipzig

Walter de Gruyter \& Co.

vormals G.J. Göschen'sche Verlagshandlung - J. Guttentag, Verlagsbuchhandlung Georg Reimer - Karl J. Trübner - Veit \& Comp. 



\section{Inhalt}

1. Der Weg nach BuBland

2. Land und Leute..................................... 11

3. Lettland als Transitland ............................. 16

4. Lettland als Agrarland; seine Holzwirtschaft .............. 26

5. Die Industrie Lettlands ........................... 33

6. Politische Verfassung Lettlands ...................... 39

7. Die wirtschaftlichen Verhältnisse Lettlands ................ 46

8. Unsere Betätigungsmöglichkeiten in Handel und Industrie....... 54

Tafeln ........................................ 61 


\section{Der Weg nach Rußland.}

Zwischen Deutschland und der Republik Lettland wurden die diplomatischen Beziehungen Ende 1919 abgebrochen und der Krieg erklärt. Der Kriegszustand blieb allerdings latent, da es weder zu militärischen Maßnahmen gekommen ist noch während seiner Dauer die Handelsbeziehungen zwischen beiden Staaten unterbrochen wurden. Am 15. Juli des Jahres $1920 \mathrm{kam}$ in Berlin ein Vertrag zustande, durch den die schwebenden Differenzen eine erstmalige Regelung fanden. Dieser Rahmenvertrag schuf die vorläufigen Grundlagen für den gegenseitigen diplomatischen und wirtschaftlichen Verkehr; im übrigen überließ er die Regelung aller Einzelfragen auf wirtschaftlichem Gebiet der Arbeit besonderer Kommissionen, die je nach Bedarf in Berlin oder Riga tagen sollten. In Ausführung seiner Bestimmungen begab sich Mitte Juli 1921 eine Kommission nach Riga, die aus 3 Vertretern von Handel und Industrie und 3 Regierungskommissaren bestand, und zu der der Autor als einer der Vertreter des Reichswirtschaftsministeriums gehörte. Ferner wirkte bei den Verhandlungen auf unserer Seite der damalige Geschäftsträger in Riga, Geheimrat von Radowitz mit, dessen intelligenter Tatkraft die deutsche Sache im Osten manches zu verdanken hat. Die Kommission hatte den Auftrag, die Verhandlungen über die wirtschaftlichen Fragen einzuleiten. Die abschließenden Besprechungen und die Unterzeichnung des Vertrages sollten in Berlin stattfinden. Das Ergebnis der sehr schwierigen Verhandlungen war die Feststellung eines Vertragsentwurfs, der in einem Verhandlungsprotokoll vom 31. August 1921 niedergelegt wurde. Bei dem darauf folgenden offiziellen Abschied wurde von lettischer Seite die Bitte an uns gerichtet, in unserer Heimat dafür einzutreten, „daß der Weg zwischen Berlin und Riga kürzer werde".

Die technischen Verbindungswege zwischen Berlin und Riga sind heute bereits so entwickelt, wie dies bei der allgemeinen Verkehrslage im Osten möglich ist. Es läuft täglich ein direkter Schnellzug zwischen den beiden Hauptstädten; durch einen im Juli 1922 abgeschlossenen Vertrag ist nicht nur ein ununterbrochener Post- 
verkehr, sondern auch ein direkter Eisenbahn-Güterverkehr zwischen Lettland und Deutschland geschaffen worden. Die Dampferverbindungen entsprechen den Bedürfnissen beider Länder, und es ist bereits im Jahre 1921 ein regelmäßiger Flugzeugverkehr zwischen Riga und Königsberg eingerichtet worden. Durch technische Mittel werden wir also vorläufig die beiden Länder sich nicht näher bringen. Es gibt aber dafür noch einen anderen Weg, die Entfernung zwischen zwei Nationen zu verringern, und der besteht darin, daß man die Kenntnis voneinander gegenseitig verbreitet. Was wir kennen, ist uns nicht mehr fremd und nicht entfernt. Wenn ich daher versuche in der vorliegenden Arbeit ein Bild der jungen lettländischen Republik zu geben, so hoffe ich, dadurch zu der Annäherung zwischen beiden Ländern beizutragen, ein Ziel, ohne dessen Verwirklichung das östliche Problem schwerlich gelöst werden wird.

Die wirtschaftliche Bedeutung des russischen Reiches für Deutschland und Europa liegt allgemein klar zutage. Das Zarenreich hat vor dem Kriege Deutschland jährlich für über 800 Millionen Goldmark Lebens- und Futtermittel geliefert. Für diese Nahrungsmittel waren wir auf Rußland angewiesen, wir können uns Ersatz dafür auf die Dauer nicht auf dem Weltmarkt beschaffen, sondern wir müssen, solange Rußland sie nicht liefert, sie entbehren, auf sie verzichten; mit anderen Worten: es muß sich unabhängig von allen Folgen, die sich für unsere Ernährung aus der Valutabewegung ergeben, aus dem höheren oder tieferen Stand der Reichsmark, die deutsche Lebenshaltung um das Maß der russischen Lieferungen verringern. Ähnlich wie Deutschland geht es, wenn auch in geringerem Maße, den westeuropäischen Staaten; die deutlich erkennbare Minderung der Lebenshaltung der Massen in England und Frankreich ist nicht zum geringsten Teil dem Ausfall der russischen Lieferungen zuzuschreiben. Fast von gleicher Bedeutung wie als Lieferant war das Zarenreich für Europa als Absatzgebiet. Von der gesamten Ausfuhrmenge deutscher Halb- und Ganzfabrikate gingen ungefähr $8 \%$ nach Rußland, das unser drittgrößter Kunde war. Große industrielle Unternehmungen bei uns waren völlig auf den Osten eingestellt, es gab Fabriken, die überhaupt für kein anderes Absatzgebiet arbeiteten als für Rußland.

Wenn aber schon vor dem Kriege die Abhängigkeit der deutschen und russischen Wirtschaft voneinander unbestreitbar war, so ist sie jetzt noch größer, die gegenseitige Verflechtung noch unlösbarer geworden. In beiden Ländern ist nämlich das Lebensniveau gering, die Löhne sind den Weltmarktlöhnen gegenüber niedrig. Diese Gleichheit schafft die natürliche Tendenz für 
beide Volkswirtschaften, sich gegenseitig anzunähern und auszugleichen. Deutschland ist, da es unter dem Weltmarktpreis produziert, das Land, auf das Rußland durch die bestehenden wirtschaftlichen Verhältnisse für den Bezug der von ihm für seinen Wiederaufbau benötigten Fabrikate hingewiesen wird, um nicht zu sagen, angewiesen ist. Von den Ländern mit höherer Lebenshaltung und teureren Produktionskosten wird es in größerem Umfang Waren nicht beziehen können.

Diese Tatsachen sind bekannt, und kein Urteilsfähiger zweifelt mehr daran, daß der Tiefstand des standard of life unserer Massen und die sich daraus herleitenden wirtschaftlichen und sozialen Schwierigkeiten erst behoben werden können, sobald unsere wirtschaftlichen Beziehungen $\mathrm{zu}$ unserem großen östlichen Nachbar wieder zum Leben gekommen sind, sobald Rußland wieder in den Kreis der europäischen Wirtschaft eingetreten, als Lieferant und Kunde ein aktiver Partner der Weltwirtschaft geworden ist. Und wer sich außerhalb Deutschlands der Einsicht über wirtschaftliche Zusammenhänge nicht verschließen will, der wird anerkennen, daß dies nicht nur eine Lebensfrage für Deutschland, sondern in allen ihren Auswirkungen eine Lebensfrage für ganz Zentraleuropa ist. Die wirtschaftliche Neuerweckung Rußlands liegt also eminent im Interesse aller europäischen Mächte und darüber hinaus auch im Interesse Amerikas, soweit diesem an einer Gesundung Europas gelegen sein muß. Aber von der theoretischen Erkenntnis bis zur praktischen Verwirklichung dieser Idee ist ein langer Weg, der mit fast unüberwindlichen Hindernissen besetzt ist. In Rußland hat sich eine Revolution entladen, wie sie an Nachdruck, Ausdehnung und Intensität wohl einzig in der Geschichte dasteht. Bei den ungeheuren Vorgängen, die sich abgespielt haben, sind die Grundpfeiler des Wirtschaftslebens erschüttert, über den Haufen geworfen und zertrümmert worden. Weder sieht die heutige russische Regierung einen Pfad hinaus aus diesem Trümmerfeld zu geordneten Verhältnissen und einer ökonomisch aufrecht erhaltbaren Produktion, noch haben sich außenstehende Staaten bisher imstande gezeigt, mit Rat und Tat wirkungsvoll einzugreifen, solange die politischen Vorbedingungen in Rußland fehlen, auf die das Kapital zu energischer Betätigung nun einmal nicht verzichten will und kann.

Wir sehen uns hier einem Circulus viciosus gegenüber, in dessen Ring keine Ansätze für einen wirtschaftlichen Wiederaufbau gedeihen können. Und doch wird dadurch nichts an der Tatsache geändert, daß der Wiederaufbau Rußlands eine unerläßlich notwendige Bedingung für die Gesundung Europas ist. Es ist uns also 
hier eine in ihrer Ausdehnung noch unübersehbare Aufgabe gestellt, deren Schwierigkeit nur übertroffen wird durch die Unerbittlichkeit, mit der ihre Lösung von uns gefordert wird.

Diese Überlegungen sind heute zum Allgemeingut geworden. Die Regierungen der westeuropäischen Länder, die sich seit Errichtung der bolschewistischen Herrschaft ängstlich von Rußland zurückhielten, haben seit mehr denn Jahresfrist die erdenklichsten Anstrengungen gemacht, sich der russischen Nation zu nähern, die russische Wirtschaft von neuem zu erschließen und der europäischen nutzbar zu machen. Welche Versuche auch immer in dieser Richtung angestellt, welche Konferenzen abgehalten wurden, zu einem positiven Ergebnis haben sie aber nicht geführt. Die europäischen Staaten haben nicht nur des öfteren einzeln mit Rußland verhandelt, sondern auch versucht, gemeinsam vorzugehen; der Plan, kapitalgewaltige internationale Kolonisationsgesellschaften zu gründen, der vor Genua zwischen England und Deutschland erörtert wurde und der eine Beteiligung auch anderer Industriestaaten vorsah, scheiterte ebenso wie die Konferenzen in Genua und im Haag, und das einzige positive Ergebnis, das erzielt wurde, nämlich der Rapallo-Vertrag, hat, wie wohl auch von seinen Verteidigern zugegeben werden muß, die Annäherung zwischen Rußland und Westeuropa um keinen Schritt vorwärts gebracht. Alle diese Versuche gingen nämlich von der Voraussetzung aus, daß das fremde Kapital in Rußland erobernd und die ökonomischen Quellen des Landes sich aneignend vordringen müsse, so wie man unter dem Kolonisationssystem ein Fremdland erobert, wirtschaftlich erschließt und ausnutzt. Dies ist aber die eine und einzige Voraussetzung, die das bolschewistische Regime niemals anerkennen und einräumen wird. Es ist dies von russischen Staatsmännern und der russischen Presse mit aller Klarheit ausgedrückt worden bei Gelegenheit der Haager Konferenz, als die Mächte zum letztenmal versuchten, dem russischen Volk als Entgelt für ein Darlehen kapitalistische Fesseln anzulegen, und zwar durch die folgenden offiziösen Worte: „Rußland wird sich nie für Geld verkaufen; die Hoffnung, daß wir vor Frankreich im Haag kapitulieren werden, ist eine schwere Selbsttäuschung. Unsere Position im Haag ist die von Genua. Rußland hat Zeit und kann warten. In einem Jahre wird unsere Lage noch besser als heute sein, und dann werden wir zu noch geringeren Konzessionen bereit sein. Ein Versailles wird es in unserer Geschichte jedenfalls nicht geben."

Diese psychologische Einstellung war allen wirklichen Kennern des Ostens schon früher bekannt; sie ist eine natürliche Folge der ge- 
schichtlichen Entwicklung der letzten Jahrzehnte. Das Übergewicht, das unter den geltenden Handelsverträgen das deutsche Element im zaristischen Rußland gewonnen, die fast absolute Herrschaft, die es auf wirtschaftlichem Gebiet sich dort verschafft hatte, war der Hauptgrund, weshalb Rußland gegen Deutschland zu Felde zog. Daher der Ausbruch des Hasses des ruhigen, uns in manchem verwandten russischen Volkes gegen deutsche Staatsangehörige bei Kriegsbeginn, ein Ausbruch, der die ganze Wut zutage legte, welche in Jahrzehnten sich aufgespeichert hatte. Die vorkriegszeitlichen Erfahrungen seiner Nation haben ein- für allemal im Russen den festen Entschluß reifen lassen, nie wieder einer fremden Nation eine wirtschaftliche Stellung einzuräumen, die ihr die ökonomischen Quellen seines Landes übereignet.

Begünstigt und genährt wird diese geistige Einstellung durch das bolschewistische Regime. Von einer bürgerlichen Regierung, die sich notwendigerweise in den althergebrachten Gedankengängen der kapitalistischen Wirtschaftsform bewegen müßte, würde wahrscheinlich die Forderung der Westmächte nach Einräumung weitgehender kapitalistischer Sicherungen als etwas Selbstverständliches angesehen werden. Ganz entgegengesetzt hierzu der Bolschewismus; denn dieser ist ein wirklicher, nicht ein eingebildeter Feind der kapitalistischen Wirtschaftsform, und er hofft noch immer auf die allgemeine sozialistische Weltrevolution. Ferner aber lenkt sich der Lauf der diktatorisch regierten militärstaatlich organisierten Sowjetrepublik mit Notwendigkeit in imperialistisch-nationalistische Bahnen. Wir erkennen heute bereits in diesem Punkte klar und offensichtlich die parallele Entwicklung mit der französischen Revolution. Wie damals die französische, so wird heute die russische Revolutionsregierung von der Prätention beherrscht, die staatlichen Verfassungen auf der Erde nach ihren Ideengängen umzugestalten, und die hierdurch hervorgerufene geeinte Opposition aller sich bedroht fühlenden fremden Staaten erzeugt als Gegenwirkung einen extremen Nationalismus im Lande, der die Erreichung seiner Ziele nur noch von innerer Geschlossenheit und starker Militärmacht erhofft. Die nationalistische Tendenz wird geschürt und gesteigert durch die panslawistische Idee, die Generationen hindurch die russische Nation beherrschte und von der es für eine kurze Zeit nach der Revolution den Anschein hatte, daß sie eingeschlummert sei; diese ist seither mit größerer Macht erwacht und drängt sich durchzusetzen. Rußland sieht heute in den von ihm abgefallenen Staaten Hochverräter; es ist entschlossen, Polen wiederzuerobern, und das Ziel seiner Diplomatie ist Konstantinopel. 
Der Regierung und Volk beherrschende Nationalismus ist zugleich der stärkste Grund, weshalb Rußland nicht bereit ist, fremden Nationen in seinem Lande ein ökonomisches Übergewicht zu geben, oder mit den Worten des Westens ausgedrückt, die politischen Garantien zu schaffen, die benötigt werden, um Kapital mit Sicherheit dorthin verleihen zu können. Deshalb auch mußten alle dahin zielenden Versuche fremder Regierungen scheitern, deshalb auch haben die langwierigen Verhandlungen englischer und amerikanischer Finanziers mit der Sowjetregierung immer und immer wieder Schiffbruch gelitten.

Vielleicht wird es heute Deutschland als erstem Staat gelingen mit Rußland zu einem Handelsvertrage zu kommen, oder deutsche Unternehmungen es erreichen, Konzessionen von der Sowjetrepublik verliehen $\mathrm{zu}$ erhalten. Dies wäre aber nicht dem Rapallo-Vertrage zuzuschreiben, wäre also nicht die wirtschaftliche Weiterentwicklung von durch einen Staatsvertrag geschaffenen politischen Beziehungen zwischen dem kommunistischen, d. h. antikapitalistischen und einem kapitalistischen Staatswesen, sondern es wäre vielmehr eine Folge der Tatsache, daß Deutschland durch den Friedensvertrag politisch machtlos geworden und durch das völlige Entgleiten der Mark wirtschaftlich derart geschwächt ist, daß Rußland nichts von ihm oder dem deutschen Kapital zu fürchten braucht.

Haben wir all dies erkannt, so wird es uns offenbar sein, daß mit den bisher versuchten Mitteln wir nicht dazu gelangen werden, Rußland aufs neue für die Weltwirtschaft nutzbar zu machen. Ein anderer Weg muß eingeschlagen werden. Das Land des Zaren ist heute ein wirtschaftliches Brachland, das Schritt für Schritt neu erschlossen werden muß. In der ganzen Kolonisationsgeschichte der Menschheit aber gibt es nur einen Weg, wie man sich ein Neuland ökonomisch eröffnet, der ist, daß man sich an den Grenzen, an den Außendistrikten festsetzt und von hier allmänlich in das Innere eindringt. Diese Außendistrikte werden für Rußland heute dargestellt in den Randstaaten. Die Randstaaten also werden die Brücke sein, über die wir nach Rußland gelangen können, während der Sprung von Berlin nach Moskau zu einem Fehltritt führen muß.

Die Randstaaten im Norden und Nordwesten Rußlands sind die Republiken Estland, Lettland, Litauen und Polen. Es wäre aber falsch, ihnen allen den gleichen Wert als Zugangswege nach dem Osten zuzuschreiben.

Polen will nicht die Brücke sein, sondern will den östlichen Handel bei sich konzentrieren, monopolisieren und ihn nach eigenem 
Belieben an Europa verteilen. Die politischen Kombinationen, auf denen es ruht, und die wirtschaftliche Verfassung seines Hinterlandes werden es ihm schwer machen, die Fäden, die nach Rußland führen, in seiner Hand zu vereinigen.

Die Republik Litauen ist zwischen Ostpreußen, Lettland und Polen eingekeilt und hat nur eine ganz kurze unmittelbare Grenze mit Sowjetrußland. Es wird heute zwar als Durchgangsweg benutzt, aber nicht vom legitimen Handel, sondern vom Schmuggel. Ohne die Bedeutung Litauens für Deutschland, die auf anderen Gebieten zu suchen ist, herabzusetzen, dürfen wir in dieser Republik nicht einen der Hauptwege sehen.

Estland mit seinem bedeutenden Hafen Reval verspricht schon mehr für die Zukunft. Bereits seit dem Jahre 1920 besteht ein reger Transitverkehr nach Rußland über Reval, das im russischen Wirtschaftsleben stets eine gewisse Rolle gespielt hat und weiter spielen wird. Aber dieser Verkehr ist zweifellos in den letzten zwei Jahren über seine natürlichen Grundlagen hinaus gesteigert worden, aus politischen Gründen, und er wird in die ihm durch die Natur des Hafens von Reval zugewiesenen, verhältnismäßig engen Grenzen im Laufe der wirtschaftlichen Entwicklung wieder zurückgeführt werden.

Desto bedeutender dagegen und ohne erkennbare Grenzen ist die Rolle, die in der Lösung des östlichen Problems der Republik Lettland zugewiesen ist, einem Lande, das durch seine geographische Lage und infolge sonstiger alteingefahrener Verhältnisse dazu prädestiniert ist, als das Vorgelände für alle wirtschaftlichen Aktionen nach Rußland zu dienen.

\section{Land und Leute.}

Das heutige Lettland besteht aus dem früheren russischen Gouvernement Kurland und Teilen der Gouvernements Livland und Witebs; es grenzt im Westen an die Ostsee, im Norden an Estland und es hat gemeinsame Grenzen mit Litauen, Polen und Sowjetrußland. Seine Seeküste ist ungefähr $464 \mathrm{~km}$ lang, sein Flächeninhalt beträgt gegen $65000 \mathrm{qkm}$, was etwa der doppelten Größe der Niederlande entspricht.

Lettland ist, mit östlichem Maßstab gemessen, reich an Städten; die 4 größten sind Riga mit ca. 300 000, Libau mit 75000 , Windau mit 22000 und Mitau mit 10000 Einwohnern. Im übrigen gibt es noch ungefähr 50 Städtchen und Flecken mit im Durchschnitt 4000 Einwohnern.

Weitaus überragt also Riga, die größte und bedeutendste Stadt, nicht nur in Lettland, sondern überhaupt in den baltischen Rand- 
staaten, die viertgrößte Stadt des früheren Russenreiches. Riga bietet, besonders wenn man sich ihm vom linken Dünaufer her nähert, ein eindrucksvolles Bild; es liegt weit ausgebreitet längs des Flußufers hingestreckt. Die Altstadt am Hafen trägt mit ihren winkligen Gassen und alten Häusern die den Hafenvierteln der Hansastädte eigentümlichen Züge altweltlicher Betriebsamkeit. Die Neustadt ist modern angelegt, es fällt gegenüber anderen Städten die Anzahl der großen Gebäude auf, die Breite der Straßen und besonders auch die Liberalität, mit der öffentliche.Anlagen in den baulich wertvollsten Teilen der Stadt angelegt sind. Der Charakter der Hansastadt drückt sich an zahllosen Beziehungen sowohl im äußeren Bilde der Stadt wie in ihren Institutionen aus. Nicht zutreffend aber ist, was häufig behauptet wird, daß Riga völlig einer deutschen Stadt gleiche, denn hierfür tritt viel zu stark das Osteuropäische hervor, sowohl in der Bauart der Häuser und in der Anlage der Stadt wie im Charakter des öffentlichen und sozialen Lebens; es stoßen vielmehr in Riga die beiden Kulturen, die deutsche und östliche, zusammen und bilden ein Gemenge, das der Stadt seinen besonderen, nur ihr eigenen Stempel aufdrückt. - Von den Einwirkungen des Krieges merkt man in der eigentlichen Stadt wenig; nur wenige Gebäude sind zerstört, und diese liegen fast ausschließlich an der Peripherie. Daß von seinen 500000 Einwohnern vor dem Kriege nur 190000 übriggeblieben waren, die jetzt im Laufe des letzten Jahres auf 300000 angewachsen sind, wird erst verständlich, wenn man in die Vorstädte kommt, die früher die Zentren der Industrie waren, und die heute verödet sind.

Von den übrigen Städten Lettlands soll hier nur noch Libau, die zweitgrößte, erwähnt werden; sie steht in einem weiten Abstand zu Riga und macht den Eindruck einer entlegenen, wenn auch betriebsamen Provinzialstadt. Das Leben und der Verkehr in ihr konzentrieren sich um den Hafen und die Schiffahrt.

Was nun die lettische Landwirtschaft anlangt, so ist bekannt, daß vor dem Kriege der adlige Großgrundbesitz vorherrschte. Die großen Güter wurden extensiv bewirtschaftet; zieht man dieses und die klimatischen und Bodenverhältnisse in Betracht, so waren die Ernteerträge nicht gering. Der Roggenertrag betrug im Gouvernement Kurland durchschnittlich 62 Puds p. Desjatine ${ }^{1}$ ) gegenüber 139 Puds in Deutschland, der Haferertrag 65 Puds gegenüber 119 Puds p. Desjatine in Deutschland, die Gerstenproduktion 64 Puds gegen 120 Puds bei uns. Uns interessiert die lettische Agrarwirtschaft aber mehr als Produzent und

1) 1 Pud $=16,4 \mathrm{~kg}, 1$ Desjatine = ungefähr $1 \mathrm{ha}$. 
Lieferant von $\mathrm{Holz}$ und Flachs. Das lettische Holz deckte vor dem Kriege einen Teil des Bedarfs von Mittel- und Westdeutschland, und zwar ging es dorthin in verarbeitetem Zustande, als Grubenholz, Schwellen- und Schnittmaterial. Seitdem nun Großrußland als Partner aus der europäischen Wirtschaft ausgeschieden ist und die Holzzufuhren aus den unerschöpflichen russischen Wäldern aufgehört haben, ist die Bedeutung der lettländischen Wälder für unsere Wirtschaft noch gestiegen. Auch der lettländische Flachs spielt in unserer Volkswirtschaft eine Rolle. Lettland hat eine Jahresproduktion, die ihm nach Deckung des Eigenbedarfs eine jährliche Ausfuhr von ungefähr 8000 bis $10000 \mathrm{t}$ ermöglicht. Hiervon hat Deutschland stets einen bedeutenden Anteil bezogen; der Flachs wird besonders bei der schlesischen Leinenindustrie geschätzt.

Lettland ist nur schwach bevölkert; es zählt ungefähr 2000000 Einwohner. Von diesen sind annähernd $90 \%$ Letten, 2 \% Russen, 4,5\% Juden und 3,5\% Deutsche. Das lettische Element war vor dem Kriege unterdrückt. Herrschend und allein maßgebend war neben dem russischen Beamten der deutschstämmige Großgrundbesitzer und Intellektuelle, die Klasse, die unter der Bezeichnung Deutsch-Balten bekannt ist. Der Lette wurde weder sozial noch intellektuell als gleichberechtigt anerkannt. Er bildete die zum Dienen bestimmte große Schicht des niederen Volkes, er leistete die geringe Arbeit, er war der Beherrschte und ohne politischen, sozialen oder wirtschaftlichen Einfluß. Die lettische Sprache wurde von der russischen Regierung unterdrückt; nur unter großen Schwierigkeiten und unter steter Gefahr schwerer Strafe konnte der Lette seine Sprache pflegen und vor dem Verfall retten. In heimlichen Zirkeln kamen die jungen Studenten zusammen und lasen dort ihre Nationaldichter. Unter diesem Druck hat die lettische Sprache gelitten und hat sich den Bedürfnissen des modernen Verkehrs nicht voll anpassen können; heute, wo sie als Ausdruck der neugewonnenen Volkseinheit und Freiheit mit allen Mitteln wieder zur allgemeinen Volkssprache gehoben werden soll, ist es notwendig, sie neu zu formen und zu ergänzen. Man holt die ihr fehlenden Begriffe und Worte aus fremden Sprachen, so besonders aus dem Englischen und Deutschen, um dadurch das Lettische für die Erfordernisse des Verkehrs zu vervollständigen.

Aus der Stellung, die der Lette früher einnahm, hat sich bei uns die Meinung verbreitet, daß er nicht nur ungebildet und charaktermäßig unzuverlässig, sondern auch wirtschaftlich unfähig sei. Diese Ansicht ist verständlich und psychologisch erklärlich bei denen, die früher in Lettland die Macht in Händen hielten und als die 
Herrschenden seit Jahrhunderten gewöhnt waren, auf alles Lettische herabzusehen; denn von Leuten, die man nur als Dienende gekannt, sie als solche angesehen hat, wird man meist nur ein geringes Urteil haben, ihre Eigenschaften und Fähigkeiten nur gering einschätzen. Der objektive Wirtschaftspolitiker und Kaufmann aber sollte dieser Einschätzung entgegentreten, denn sie ist unzutreffend. $\mathrm{Ob}$ und wieweit der Lette als Geschäftsmann zuverlässig ist, darüber kann man wohl kein summarisches Urteil abgeben, und ich habe keine Gelegenheit gehabt, eigene Erfahrungen zu machen. Kommt man aber mit Nationalletten aus den intellektuellen Kreisen in nähere Fühlung, so wird man finden, daß sie an Bildungsformen und geschäftlicher Routine gegen den Westeuropäer nicht zurückstehen. Wer also aus solch vorgefaßter Meinung heraus es ablehnt, mit Letten in geschäftliche Beziehungen zu treten, oder wer glaubt, daß sie etwa dem Zentraleuropäer nicht gewachsen seien, der irrt sich und wird dadurch leicht zu Fehlern in Auffassung und Handeln verleitet werden.

Die Deutschstämmigen haben durch den Krieg am meisten gelitten. Der Großgrundbesitz war fast ausschließlich in ibren Händen, von dem Großhandel und der Industrie etwa $80 \%$. Die meisten der Großgrundbesitzer nun haben das Land verlassen müssen; von den früher reichen einflußreichen baltischen Handelsfirmen ist nur noch ein kleiner Teil übrig geblieben, und auch diese haben ihr Vermögen zum großen Teil, ihren öffentlichen Einfluß gänzlich eingebüßt.

Was schließlich das jüdische Element anlangt, so tritt es zwar politisch wenig und sozial gar nicht in Erscheinung, nichtsdestoweniger ist es eine Macht, denn die Juden haben wichtige Zweige des Handels an sich gebracht, so den Innen- und Außenhandel mit Lebensmitteln, und unter der Oberfläche sollen sie auch in finanziellen Dingen starken Einfluß ausüben.

Ein deutscher Industrieller, der als besonderer Kenner östlicher Verhältnisse in weiten Kreisen geschätzt wird, hat einmal Lettland das „Belgien des Ostens“ genannt. Dieser Vergleich legt schlaglichtartig die ökonomische Struktur Lettlands dar. Wenn Belgien heute das am stärksten industrialisierte Land der Erde ist, so liegt die Ursache hierfür nicht, wie häufig behauptet wird, in seinem Rohstoffreichtum; von der gesamten Kohle, die Belgien verbraucht, wird im Lande nur $65 \%$ gefördert, der Rest importiert. Seine ausgedehnte Eisenindustrie bezieht fast das gesamte Roherz aus dem Ausland, nur 11/2\% des Erzkonsums wird im Lande gewonnen. Die Wolle, Baumwolle und Seide, die seine weithin gerühmte 
Textilindustrie verarbeitet, kommt beinahe ausschließlich aus Übersee. Es sind also nicht seine Rohstoffquellen, die aus Belgien fast eine einzige große Industriestätte gemacht haben, sondern wir müssen die Ursache hierfür in seiner geographischen Lage suchen. Das Küstenland Belgien ist dem industriereichsten Teil Zentraleuropas vorgelagert, und daher ist es dessen natürlicher Ein- und Ausfuhrhafen ${ }^{1}$ ). Durch den Rhein und durch ein weitverzweigtes Kanal- und Bahnnetz steht es mit seinem Hinterland in Verbindung, für das es die Gütervermittlung bewerkstelligt, es betreibt ein Speditionsgewerbe im großen. Hierdurch schafft es für sich selbst billige Frachten sowie günstige und häufige Schiffs- und Landtransportgelegenheiten, was es in den Stand setzt, auch für eigene Rechnung billig Rohstoffe heranzuziehen, die es dann im Lande verarbeitet. Dieses ist die eigentliche Grundlage der belgischen Industrie. Es wurde den Deutschen, die während der Besatzungszeit sich in das Studium der belgischen Vulkswirtschaft vertieften, ebenso augenfällig wie zunächst unverständlich, welches überwiegende Gewicht die belgische Regierung auf die Förderung des Hafens von Antwerpen gelegt hatte, wie es kaum eine wirtschaftspolitische Maßnahme gegeben hatte, bei der dieser Gesichtspunkt für sie nicht entscheidend gewesen wäre; die Lösung des Rätsels liegt in der oben angedeuteten Richtung, in der Tatsache, daß der Transitverkehr die Grundlage der belgischen Industrie war, in der Erkenntnis, daß mit dem Hafen Antwerpen die belgische Industrie steht und fällt.

Und nun zu Lettland. Wenn wir die Volkswirtschaft seines Staatsgebietes vor dem Kriege in ihre Einzelteile zerlegen, so erkennen wir hier ebenso wie in Belgien drei scharf gegliederte wirtschaftliche Funktionen, und zwar war Lettland: Transitland, d. h. Durchfuhrland infolge seiner Küstenlage und Hafenplätze; seine drei Häfen Riga, Libau und Mitau schlugen ungefähr 20-25\% der gesamten russischen Ein- und Ausfuhr um. Es war zweitens Agrarland, denn es versorgte nicht nur sich selbst mit allen Erzeugnissen der Landwirtschaft, sondern war landwirtschaftliches Überschußland und Großexporteur von Holz und Flachs. Es war schließlich Industrieland, denn es beschäftigte allein in den Fabriken von Riga 85000 Arbeiter, das bedeutet, daß fast $2 / 3$ der Rigaer Einwohner unmittelbar von der Industrie lebten.

Dieses war der Zustand vor dem Kriege, solange das heutige Lettland ein Teil des Zarenreiches war, sich also als eines ihrer

1) Jch verweise auf das vorzügliche Werk von Schumacher: Antwerpen, seine Weltstellung und Bedeutung für das deutsche Wirtschaftsleben. München, 1916. 
Glieder in die großrussische Gesamtwirtschaft einordnete, von welcher ihm zwei seiner wirtschaftlichen Einzelfunktionen zugewiesen wurden. Daß sich diese Betätigungsgebiete der lettischen Wirtschaft in den letzten Jahren gegeneinander schon stark verschoben haben, wird mit nachstehenden Zahlen dargetan. Im Staatsgebiet der Republik Lettland waren tätig:

in der Landwirtschaft

vor dem Kriege (im Jahre 1897) 48,8 \% der Bevölkerung, jetzt $79,5 \%$;

in der Industrie $21,4 \%$ der Bevölkerung, jetzt $6,6 \%$;

im Handel und Speditionsgewerbe $8 \%$ der Bevölkerung, jetzt $3,9 \%$.

Die Zahlen drücken eine Dezimierung der Industrie und ein starkes Abnehmen von Handel und Gewerbe aus, hervorgerufen durch den Abfluß der Bevölkerung auf das flache Land. Diese Bewegung ist typisch für eine Übergangsperiode, ist durchaus erklärlich in dieser Zeit der Revolutionen, Separationen und wirtschaftlichen Katastrophen; sie aber ohne weiteres als etwas Dauerndes und Endgültiges anzusehen, kann uns nicht in den Sinn kommen, vielmehr ist es gerade die Aufgabe dieser Arbeit, zu untersuchen, ob Lettland imstande sein wird, trotz seiner Abtrennung von GrobRußland und trotz der politischen und wirtschaftlichen Umwälzungen in Rußland seine früheren volkswirtschaftlichen Funktionen wieder auszuüben. Diese Frage ist von eminent praktischer Bedeutung für jeden, der sich in Lettland wirtschaftlich betätigen will, der dort etwas unternehmen und Kapital investieren will, und unter diesem Gesichtspunkt wird in nachstehendem auf die drei erwähnten Wirtschaftsgebiete oder Funktionen näher eingegangen werden.

\section{Lettland als Transitland.}

Ich habe von Belgien als dem Hafenland für Zentraleuropa gesprochen und hiermit die Lage Lettlands zum europäischen Rußland verglichen, indem ich bereits kurz auf seine Küstenlage und seine Häfen hingewiesen habe, ebenso auf die natürlichen Transportwege, die es mit seinem Hinterlande verbinden. In Nachstehendem soll dieses nun vertieft werden. Meine Ausführungen werden dabei beschränkt werden auf die beiden wichtigsten Häfen Riga und Libau.

Die Lage von Riga ist für einen Hafen günstig. Es liegt in einer Meeresbucht derart geschützt, daß man am Strande kaum einen luftigen Hauch spürt, ja den eigentlichen Seegeruch vermißt, der uns unzertrennlich erscheint von dem Ost- und Nordseestrand. 
Mit der Küste, die ungefähr eine Stunde entfernt liegt, ist Riga verbunden durch die Düna, die sich kurz vor ihrer Mündung mit der kurländischen Aa vereinigt. Die Düna hat bei Riga eine Breite von $800 \mathrm{~m}$, ein stattlicher, würdiger Fluß. Sie ist nur von Riga ab bis zur Mündung schiffbar. Ihre Tiefe beträgt auf dieser Strecke bei normalem Wasserstand und vorausgesetzt, daß die ständig erforderlichen Bagger- und Stromarbeiten nicht vernachlässigt werden, 25-28 Fuß, genügend also für Schiffe bis zu 4000 Registertonnen. Der Hafen hat große, sich lang hinziehende Kaimauern, aber wenig mechanische Ladevorrichtungen, wie Kräne; diese waren auch im Frieden nur mangelhaft vorhanden. Im Schiffsverkehr, nach Registertonnen gemessen, stand Riga unter den Ostseehäfen an fünfter oder sechster Stelle. Es waren zu Zeiten, besonders während der Saison für die Holzverladungen, bis zu 35 Seedampfer im Hafen.

Heute ist der Schiffsverkehr natürlich viel geringer, er befindet sich aber immerhin in aufsteigender Linie, wie folgender Vergleich für die gesamten lettischen Häfen zeigt, von denen auf Riga der Hauptanteil entfällt.

\begin{tabular}{|c|c|c|c|c|c|}
\hline & & 921 & & 22 & $\begin{array}{c}\text { Zunahme } \\
\text { bzw. }\end{array}$ \\
\hline & Schiffszahl & Nettotonnen & Schiffszahl & Nettotonnen & \\
\hline $\begin{array}{l}\text { Es liefen in lettischen Häfen } \\
\text { ein ................. } \\
\text { Es liefen aus lettischen Häfen } \\
\text { aus ................... }\end{array}$ & $\begin{array}{r}2104 \\
\text { 1) } 2038\end{array}$ & $\begin{array}{l}785000 \\
774000\end{array}$ & $\begin{array}{l}2878 \\
2863\end{array}$ & $\begin{array}{l}1294000 \\
1283000\end{array}$ & $\begin{array}{l}+65 \% \\
+65 \%\end{array}$ \\
\hline
\end{tabular}

Was nun die Verbindung Rigas mit seinem Hinterland anlangt, so hat allerdings die Düna und die mit ihr verbundene Aa nicht die Bedeutung für den Rigaer Verkehr wie etwa der Rhein für Antwerpen. Der Fluß ist oberhalb Rigas nicht schiffbar, es verkehren auf ihm nur kleine Boote, die für die Güterzufuhr keine Rolle spielen. Die Düna war daher im wesentlichen auch nur die Anfuhrstraße für Holz, welches dem Werte nach $18 \%$, dem Verschiffungsraum nach 65-75\% der Rigaer Gesamtausfuhr ausmachte. Die neben dem Holz für den Rigaer Umschlagverkehr wichtigsten Artikel: Flachs, Eier, Häute, Felle und Getreide, die dem Werte nach ungefähr $60 \%$ der Rigaer Gesamtausfuhr betrugen, und weitere $10 \%$ Waren geringerer Bedeutung, also zusammen ungefähr $70 \%$ der Rigaer Gesamtausfuhr, gelangten auf dem Bahnwege aus dem Innern des Landes zum Hafen.

1) Der Unterschied in der Zahl der ein- und ausgelaufenen Schiffe dürfte auf mangelhafter statistischer Erfassung beruhen; für die Beurteilung des Hafenverkehrs ist nur die Tonnenzahl von Bedeutung. 
Eisenbahnen sind künstliche Transportwege, und die Tatsache, daß $70 \%$ der Ausfuhrwaren mittels der Bahn nach Riga geführt worden sind, läßt die nicht selten gehörte Behauptung berechtigt erscheinen, daß der Hafen künstlich großgezogen worden, daß also Rußland nicht unbedingt auf ihn angewiesen sei, woraus folgere, daß die heutige russische Regierung imstande sein werde, wenn sie die für Erweiterung bestehender Hafenanlagen erforderlichen Kosten dafür aufwende, den Güterverkehr über andere der bolschewistischen Republik angehörende Häfen zu lenken, nachdem jetzt Riga nicht mehr zum Russischen Reich geböre. Eine Bestätigung dieser Ansicht könnte man bereits in den gegenwärtigen Verhältnissen erblicken. Es ist bekannt, daß die Sowjetregierung seit etwa zwei Jahren Riga als Einfuhrhafen boykottiert, daß sie die von ihr im Ausland eingekauften Waren über Petersburg und Reval leitet und keine Aufwendungen scheut, den Petersburger Hafen auszubauen, um ihn zum Mittelpunkt des Umschlagverkehrs zu machen. RussischeDiplomaten haben es ausdrücklich bestätigt, daß mit allen Mitteln staatlicher Förderung versucht werden solle, Petersburg auf Kosten von Riga zum Haupthafen des europäischen Rußland zu machen. Lettischerseits fürehtet man allerdings diesen Wettbewerb nicht, man ist vielmehr der Überzeugung, daß Riga zum Hauptausfuhrhafen Rußlands im Norden sich auf Grund der von der Natur geschaffenen Tatsachen entwickelt habe, und daß keine Maßnahmen der Politik auf die Dauer diese natürlichen Bedingungen werden außer Spiel setzen können.

Ist der lettische Standpunkt der richtige oder war der Hafen von Riga vor dem Kriege künstlich groß gezogen und kann er durch andere Ostseehäfen ersetzt werden? Hiermit steht und fällt die Bedeutung Lettlands als Durchfuhrland.

Wenn der Hafen von Riga über seine natürliche Bedeutung hinaus künstlich gefördert worden war, so setzt dies voraus, daß die absolutistische Regierung ein besonderes Interesse - politischer oder wirtschafclicher Art - an der Hebung des Hafens gehabt hat, etwa wie die belgische Regierung an Antwerpen. Dann hätte sie dieses Interesse öffentlich dokumentiert durch Schaffung eines auf Riga zulaufenden Eisenbahnnetzes, gleichgültig, ob eine Rentabilität desselben zu erwarten war oder nicht, durch eine auf Rigaer Interessen eingestellte Tarifpolitik, durch Hafen- und Stromregulierungsarbeiten und ähnliche technische Fürsorge. Nichts von diesem war der Fall. Im Gegenteil hat die Zarenregierung seit Jahren eine starke Abneigung gegen Riga unverhohlen an den Tag gelegt und alles getan, um auf Kosten dieser Stadt den Seeverkehr über Peters- 
burg und die südrussischen Häfen zu leiten. Der Dezernent des Rigaer Börsenkomitees schreibt hierüber wie folgt:

„Aus obigem erhellt, daß Rigas auswärtiger Handel ... ausschließlich der stets regen Initiative ... der Rigaer Kaufmannschaft und der Großindustrie zuzuschreiben ist, die dabei ganz auf sich selbst angewiesen waren, da ihnen seitens der russischen Regierung im großen und ganzen nicht nur keinerlei Unterstützung und wohlwollende Förderung zuteil wurde, sondern ihnen sogar bei ihren Bestrebungen immer wieder Hemmnisse jeglicher Art in den Weg gelegt wurden. Die Entwicklung des ... Rigaer Hafens, ... sollte eben auf künstliche Weise niedergehalten werden, zu welchem Zwecke seine vitalsten Bedürfnisse vielfach vernachlässigt wurden, so u. a. auch durch Verschleppung der Entscheidung der wichtigsten seitens der Kaufmannschaft angeregten Fragen. Dabei wurde andererseits St. Petersburg in jeder Hinsicht, beim Bau von Eisenbahnen, Wasserstraßen, bei Erstellung vonTarifen usw. gefördert, namentlich aber wurden enorme Staatsmittel für die weitere Ausgestaltung und Ausrüstung des Hafens aufgewandt, obgleich eine derartige Bevorzugung des St. Petersburger Hafens schon aus dem Grunde nicht gerechtfertigt ist, weil er eben infolge von Eisschwierigkeiten 6 Monate hindurch für Schiffe nicht zugänglich ist."

Auch in ihrer Handelspolitik hat die zaristische Regierung sich über die Interessen Rigas hinweggesetzt. So hat sie im deutschrussischen Handelsvertrag vom Jahre 1894 durch Gewährung direkter Durchgangstarife die deutschen Häfen Königsberg, Memel und Danzig frachtlich mit Riga gleich-, d. h. die fremdstaatlichen Häf en ebenso günstig gestellt wie Riga. Die Einstellung der zaristischen Regierung gegenüber Riga leitet sich aus politischen Erwägungen her und ist daher verständlich.

Trotz des gänzlichen Fehlens staatlicher Gunst jedoch stieg die Bedeutung Rigas als Warenumschlagsplatz ständig, und dies geschah offensichtlich auf Kosten der Hauptstadt Petersburg, deren Hafenverkehr es seit dem Jahre 1900 endgültig überflügelt hatte. Hierüber gibt Tabelle 1 (S. 61) Auskunft.

Die eigentliche, natürliche Basis eines Hafens ist sein Hinterland, ist das geographische Gebiet, für das er den Güterverkehr zu vermitteln, das er zu versorgen hat. Ist dieses Gebiet auf ihn angewiesen, wie etwa die Kohlen von Wales auf Cardiff oder die Waren von Manchester auf Liverpool, das belgische Industriegebiet auf Antwerpen, dann ist die Hafenfunktion eine natürliche, eine fast unabänderliche. 
Zunächst muß man sich klarmachen, welches denn eigentlich das Hinterland war, das den Hafen von Riga speiste, ihm Leben und Wachstum gab. Hierbei will ich mich zunächst dem Ausfuhrverkehr zuwenden und mich dabei auf die früher erwähnten fünf Hauptausfuhrartikel, Holz, Getreide, Flachs, Felle und Häute, und Eier beschränken. Die Statistik ergibt nun folgendes:

Geschnittene Hölzer kamen aus einem Umkreis von zirka $1200 \mathrm{~km}$ Radius, und zwar nordöstlich aus dem jetzigen Estland, östlich und südöstlich aus Gegenden um Jaroslaw, Moskau, Kjäsan. Das Versorgungsgebiet Rigas reichte also ungefähr bis zur Mitte der Linie Petersburg-Astrachan und östlich noch beträchtlich darüber hinaus.

Das auf der Düna geflößte Holz stammt zu ungefähr $70 \%$ aus den Gouvernements Witebsk und Smolensk, also aus einer Entfernung von $400 \mathrm{~km}$, halbwegs zwischen Riga und Moskau; weitere je $10 \%$ kamen aus Wilna (ca. $300 \mathrm{~km}$ südwestlich von Riga) und Livland.

Weizen und Roggen kamen aus den Ural-Gouvernements Orenberg, Ufa, Samara, also aus der äußersten Südostecke des europäischen Rußland, aus einer Entfernung von $2500 \mathrm{~km}$.

Das Hinterland für Flachs bildete außer den baltischen Provinzen ein Komplex, der im Westen begrenzt wurde durch das Gouvernement Grodno, im Nordosten ungefähr bis zur Höhe von Moskau reichte, im Osten bis an die Wolga und noch weiter darüber hinaus in die nordöstlichen Departements Kostrona und Wologda ging.

Eier kamen über Moskau und Kasan aus den südöstlichen und südlichen Gouvernements Europäisch-Rußlands, aus den Provinzen, die sich von der Südspitze des Uralgebirges bis zum Asowschen und Schwarzen Meer hinziehen. Daß man die Eier, die aus diesen Provinzen stammten, nicht über die Südhäfen, sondern über Riga versandte, ist besonders bemerkenswert und beweist vielleicht am klarsten die zwanghafte Notwendigkeit, mit der Südrußland seinen Ausfuhrhafen in Riga suchte und fand.

Die Häute und Felle, die nach Riga gelangten, kamen aus dem Süden, u. a. vom Kaspischen See die Wolga hinauf, dann wurden sie umgeschlagen und mit der Eisenbahn nach dem Norden geführt.

Eine Zusammenfassung dieser Versorgungsgebiete zeigt, daß sich fast das gesamte europäische Rußland mit Ausnahme der nordöstlichen Provinzen des Rigaer Hafens bediente. Aus den entferntest gelegenen Teilen, quer durch das ganze Russenreich hindurch, auf 
Entfernungen von 3000 km, wurden die Güter nach Riga befördert, um von dort verschifft $\mathrm{zu}$ werden. Ja, auch aus den südlichen Provinzen wurde Riga gespeist, Provinzen, die selbst bedeutende Häfen, wie Odessa, Rostow, Nowarascisk und Taganrog, besaßen.

Wenn man sich dies vergegenwärtigt und dazu die vorhin erwähnte Tatsache fügt, daß trotz der unfreundlichen Haltung der zaristischen Regierung die Stadt ihre Bedeutung als Hafenplatz nicht nur behauptet, sondern sich vor dem Kriege zum bedeutendsten russischen Ostseehafen entwickelt hatte, so ist dies wohl ein überzeugender Beweis dafür, daß diese Entwicklung eine natürliche war, daß Riga seine Stellung als Hafen den von der Natur gegebenen Verhältnissen verdankt und nicht künstlicher Förderung, und daß diese natürlichen Bedingungen sich auch in Zukunft durchsetzen werden.

Es wäre nun zu fragen, worin diese natürlichen Grundlagen bestehen; sie lassen sich wie folgt zusammenfassen:

1. Als wichtigster Faktor erscheint die geographische Lage Rigas im Verhältnis zu England, Deutschland, Belgien und Dänemark, Staaten, die als Lieferanten sowohl wie als Kunden in der russischen Handelsbilanz den ersten Platz einnahmen. Infolge seiner geographischen Lage fügte sich Riga organisch in den regen Schiffsverkehr ein, der zwischen den Haupthäfen dieser Länder bestand; es wurde mühelos einer seiner Stützpunkte. Da die Entfernung zwischen jenen Staaten und Riga verhältnismäßig gering war, so konnten billige Frachten erstellt werden, die Beförderungszeit war kurz und die Verschiffungsgelegenheiten häufig und günstig. Deshalb zog es, um ein Beispiel zu nennen, der Händler vor, Eier aus der Provinz Charkow mehrere $1000 \mathrm{~km}$ mit der Bahn nach Riga und von hier aus per Schiff nach London zu senden, als sie über Taganrog oder Odessa zu verschiffen, die nur einige hundert Bahnkilometer vom Erzeugungsort entfernt waren, die aber weniger vorteilhafte Seefrachten und Verschiffungsgelegenheiten boten. Der Weg über Riga war schneller, billiger und daher allgemein befriedigender.

2. Als zweite der natürlichen Grundlagen des Hafens sind seine günstigen Eisverhältnisse zu erwähnen. In der Zeitspanne von 1884 bis 1914 war die Schiffahrt im Durchschnitt nur 43 Tage im Jahre wegen Eises geschlossen. Während dieser Periode gab es 5 Jahre, in denen der Hafen völlig offen blieb, der Schiffsverkehr also überhaupt nicht ruhte. Aber auch die genannte Vereisungsdurchschnittszeit läßt sich erheblich verringern. Der Hafen wird nämlich nicht etwa geschlossen, weil die Düna zufriert, denn der Fluß läßt sich durch kleine Eisbrecher leicht offen halten; vielmehr hat die Sperre ihre Ursache in Eismengen, die sich bei der Meerenge 
am Eingang zum Meerbusen beim Kap Domesnes stauen. Auch hier hätte durch Eisbrecher bedeutende Erleichterung geschaffen und die Sperrzeit erheblich verkürzt werden können, wenn die zaristische Regierung der Stadt Riga ein größeres Wohlwollen gezeigt hätte. Da das Gegenteil der Fall war, hat es die Kaufmannschaft nicht durchsetzen können, daß dem Hafen ein ständiger Eisbrecher zugewiesen wurde; man blieb vielmehr auf gelegentliche Hilfe von Eisbrechern angewiesen, die in Libau oder Reval stationiert waren, bei Eisnot stets neu angefordert werden mußten, und die nach glücklicher Überwindung aller bürokratischen Hemmnisse stets nur mit großem Zeitverlust eintrafen. Im Jahre 1912 schaffte sich daher die Rigaer Kaufmannschaft einen eigenen Eisbrecher an. Das Ergebnis war, daß der Hafen im Winter 1912/13 nur 27 Tage, im Winter 1913/14 nur 29 Tage geschlossen war. Diese günstigen Eisverhältnisse setzen Riga besonders auch gegenüber Petersburg in Vorteil, dessen Hafen durchschnittlich 6 Monate im Jahre geschlossen ist.

3. Die Tatsache, daß Riga der Mündepunkt des durch die Düna und die beiden Aaflüsse gebildeten Flußsystems, also der natürliche Stapelplatz für das auf diesen Flüssen herangeführte Holz ist, muß als ein weiterer determinierender Faktor für seine Stellung als Hafenplatz angeführt werden. Nimmt man den Geldwert als Maßstab, so betrug das Holz von der gesamten Ausfuhr Rigas zwar nur $18 \%$; anders aber war bei seinem sperrigen Charakter die Bedeutung des Holzes als Ladegut, denn es beanspruchte ungefähr $65-75 \%$ des gesamten Ausfuhrladeraumes. Weil nun große Mengen Holz dauernd der Verschiffung harrten - Riga war der größte Holzausfuhrhafen in Europa -, war stets ein Stapelartikel vorhanden, der den mit Einfuhrwaren eingelaufenen Dampfern eine Rückfracht gewährte; infolgedessen verließ im Durchschnitt der letzten 20 Jahre nur 2,8-3\% des ausgehenden Laderaums den Hafen mit Ballast beladen, 97 \% war wirtschaftlich ausgenutzt und zahlte dem Reeder eine Fracht. Dies wirkte natürlich günstig auf die gesamte Frachtenlage und förderte die Lebhaftigkeit des Schiffsverkehrs. Kein Wunder, daß sich der Rigaer Schiffsverkehr ständig hob und im Jahre 1913 fast doppelt so hoch war als im Jahre 1900.

4. Aus dem Geschilderten ergibt sich schon die enge Wechselwirkung, die zwischen Ausfuhr und Einfuhr besteht, eine Tatsache, die bei der Beurteilung von internationalen Handelsbeziehungen im allgemeinen viel zu wenig gewürdigt wird, und die wir sogleich für das vierte, noch zu erwähnende Moment in Anspruch nehmen, 
nämlich Rigas Eignung als Einfuhrhafen. Weil nämlich die Verschiffungsbedingungen für die russischen Ausfuhrwaren in Riga die geschildert günstigen waren, nahm automatisch die ausländische Einfuhr ihren Weg ebenfalls dorthin, und zwar infolge der vorteilhaften Frachten und der vorhandenen schnellen und häufigen Schiffsverbindungen. Was aber die Stellung von Riga als Einfuhrhafen fernerhin förderte und befestigte, war die Tatsache, daß für den Weitertransport der Einfuhrware nach dem Innern Rußlands, das heißt nach den Hauptzentren des Verbrauchs, Riga geographisch vorteilhafter liegt als die meisten seiner Konkurrenten unter den russischen Ostseehäfen, insbesondere Libau und Reval. Ein Blick auf die Karte beweist dieses, es wird auch leicht durch Zahlen bewiesen.

Ich hoffe, in vorstehendem dargetan zu haben, daß, wenn das gesamte europäische Rußland sich des Hafens von Riga bediente, dieses etwas notwendig Bedingtes war, bedingt durch die geographischen und topographischen, also im tiefsten Sinne wirtschaftlichen Verhältnisse. Die oben erwähnten Faktoren sind, da sie auf die Natur selbst zurückzuführen sind, durch die politischen Ereignisse nicht berührt worden, konnten durch sie nicht berührt werden, was notwendigerweise zu dem Schluß führt, daß sie auch in Zukunft unabhängig von der Politik maßgebend für die Stellung Rigas als Hafenplatz sein werden. Ob das europäische Rußland in seiner jetzigen politischen Struktur bestehen bleiben wird, das wissen wir nicht. Wie aber immer die politische Landkarte im Osten gestaltet sein mag, eines darf als sicher gelten, nämlich, daß das durch das europäische Rußland dargestellte geographische Gebiet Riga auch in Zukunft als sein wirtschaftliches Hauptausfalltor benutzen wird; hiermit aber ist aller menschlichen Berechnung nach die Zukunft von Riga als Hafen und damit zugleich die von Lettland als Durchfuhrland bestimmt, und zwar in dem Sinne, daß Lettland auch weiterbin das Küsten-Transitland für Rußland, die Brücke zwischen Westeuropa und Rußland bleiben wird. Damit bestätigt sich für uns die Wichtigkeit Lettlands als Aufmarschgebiet für alle wirtschaftlichen Unternehmungen, die uns und andere Westmächte nach Rußland hineinführen.

Was Libau anlangt, so stand es unter den Ostseehäfen des Zarenreiches zwar an zweiter Stelle, doch ist der Abstand zwischen ihm und Riga sehr bedeutend. Während in Riga $15 \%$ des gesamten russischen Außenhandels umgeschlagen wurden, fielen auf Libau nur ungefähr $4 \%$. Die Hauptausfuhrartikel waren Getreide, Holz und Spiritus. Die geographische Lage Libaus ist ungünstiger als die seines großen Konkurrenten. Als Hinterland können ihm 
im wesentlichen nur die westlichen Provinzen des früheren Zarenreiches zugesprochen werden, darunter das jetzige Litauen und Teile von PJlen. Hieraus ergibt sich schon ein großer Nachteil; die Verbindung Libaus mit seinem natürlichen Hinterlande nämlich hängt zum Teil von dem guten Willen und der Interessenpolitik zweier fremder Staaten, nämlich von Litauen und Polen, ab, welche durch eine unfreundliche Eisenbahn- und Frachtenpolitik Libau wirtschaftlich isolieren können. Infolgedessen erscheint die Zukunft dieser Stadt als Hafenplatz auch nicht unbedingt gesichert; keinesfalls aber treffen auch hier die Erwägungen zu, die für Riga gelten, nämlich, daß das frühere Hinterland von Libau zwangsweise wieder sich dieses Hafens wird bedienen müssen. Es soll hierauf besonders hingewiesen werden, weil man versucht, deutsches Kapital für den Plan zu interessieren, den Libauer Kriegshafen in einen Freihafen umzuwandeln. Da dieses Projekt und seine möglichen Auswirkungen seit längerer Zeit in Fachkreisen bekannt war, begrüßte ich die Gelegenheit, die Frage in Libau an Ort und Stelle studieren zu können, wozu die lettische Regierung bereitwilligst die Möglichkeit gab. Der Libauer Kriegshafen ist eines der interessantesten Werke in Lettland. Die zaristische Regierung hat einen mit dichtem Wald bestandenen Flecken Erde in einen großen künstlichen Hafen umgeschaffen mit einer Fahrrinne von mehreren Kilometern Länge und einigen hundert Metern Breite, und sie hat ihn mit ausgedehnten Werftanlagen, Docks und Kasernements für mehrere Regimenter ausgestattet. Um einen Begriff von der Großzügigkeit der Anlagen zu geben, sei erwähnt, daß die Reitmanege, die zu den Kasernements gehört, über $250 \mathrm{~m}$ lang ist. Nachdem man 16 Jahre lang mit Tausenden von Arbeitern Tag und Nacht an dem Hafen gearbeitet und ihn fast vollendet hatte, kam der russisch-japanische Krieg. Die Erfahrungen, die man in seinem Verlauf mit der in Port Arthur eingeschlossenen Flotte machen mußte, brachten die russische Marineleitung zu der Überzeugung, daß der Libauer Hafen kein sicherer Schutz für Kriegsschiffe sein würde; mit echt russischer Großzügigkeit war man schnell entschlossen, und es wurde unverzüglich zum Bau eines neuen Kriegshafens in Reval geschritten und die Libauer Anlage zur Torpedobasis bestimmt.

Der heute brachliegende Kriegshafen soll jetzt also zu einem Freihafen ausgebaut und mit allen für einen großzügigen Verkehr berechneten maschinellen und technischen Anlagen versehen werden. $\mathrm{Ob}$ später der Freihafen florieren, das investierte Kapital sich rentieren würde, bleibt abzuwarten; heute aber fehlen noch alle Vorbedingungen hierfür. Denn weder läßt sich die Zukunft Libaus 
als Hafenplatz übersehen, noch ist bereits der wichtigste Faktor, der einzige, der dem geplanten Freihafen überhaupt Lebensberechtigung geben würde, vorhanden, nämlich der russische Güterverkehr; nur wenn dieser in dem Ausmaß, wie er vor dem Kriege bestand, wieder aufgelebt ist, hat der Freihafen einen Zweck, ohne ihn würdé er ebenso tot daliegen wie heute der Kriegshafen. Unter den heutigen Verhältnissen ist also das erwähnte Projekt verfrüht, die Zeit ist noch nicht reif dafür. Wer nichtsdestoweniger beabsichtigt, heute Kapital hierin zu investieren, sollte jedenfalls nicht unterlassen, reiflich zu prüfen, ob er die Zukunft Libaus als Hafen für genügend gesichert hält.

Dagegen möchte ich nicht verfehlen, an dieser Stelle eines anderen Projektes Erwähnung zu tun, das für die Transitfunktion Lettlands ebenfalls von Bedeutung sein würde, aber vielleicht mehr Aussicht besitzt, in absehbarer Zeit verwirklicht zu werden. Es handelt sich um die Regulierung und Schiffbarmachung der Düna oberhalb von Riga. In ihrem oberen Lauf, und zwar zwischen Witebsk und Dünaburg, ist der Fluß schiffbar, und es verkehren auf $\mathrm{ihm}$ Boote mit einem Tiefgang bis zu $21 / 2 \mathrm{~m}$. Hinter Dünaburg verringert sich nicht nur die Tiefe des Bettes, sondern es sind bei zwei Ortschaften in der Nähe von Riga, bei Kockenhusen und Dahlem, Stromschnellen vorhanden, die den Fluß zwischen den beiden genannten Verkehrszentren unschiffbar machen.

Es hat nun früher bereits die Absicht bestanden, durch Vornahme von Sprengungen und Anlage von Schleusen dieser Hindernisse Herr zu werden, der Krieg hat aber die Arbeiten an dem Projekte zu einem vorzeitigen Abschluß gebracht. Seither hat sich eine deutsche Gesellschaft erneut mit dem Projekt beschäftigt, die Undurchsichtigkeit der politischen Verhältnisse und die ungünstige Gestaltung des Geldmarktes zwangen jedoch dazu, alle Pläne für dessen Durchführung bis auf günstigere Zeiten zurückzustellen.

Die wirtschaftliche Bedeutung der Regulierung der Düna liegt in zweierlei Richtung. Die Eröffnung des $4-500 \mathrm{~km}$ langen Wasserweges würde eine neue leistungsfähige Handelsstraße von Riga nach dem Innern des Landes schaffen; die von ihr berührten Landesteile, die fruchtbar und reich an natürlichen Schätzen sind, würden wirtschaftlich neu erschlossen werden und ihre gesteigerte landwirtschaftliche Produktion mit geringen Transportkosten nach Riga führen. Die Steigerung, die der Hafenverkehr dadurch erfahren müßte, ist also offensichtlich. Hinzu kommt aber, daß man durch Verwertung der Wasserkräfte bei Kockenhusen und Dahlem genügend elektrische Energie gewinnen könnte, um damit die ge- 
samte Rigaer Industrie in ihrer früheren Ausdehnung zu versorgen, und es wird sogar behauptet, daß genügend Kraft vorhanden sein würde, um einen Teil der Staatsbahnen damit zu bewegen.

\section{Lettland als Agrarland; seine Holzwirtschaft.}

Als zweite volkswirtschaftliche Funktion Lettlands haben wir die Produktion und Ausfuhr landwirtschaftlicher Rohstoffe erwähnt. Die landwirtschaftlichen Produktionsbedingungen in Lettland sind seit Bestehen der Republik staatlichen Eingriffen von grundlegender Bedeutung unterworfen worden. Wie auch sonst in Rußland, bestand unter dem Zarenregime die landwirtschaftliche Fläche im wesentlichen aus Großbesitz, dieser befand sich in Händen alteingesessener Familien, die man als die baltischen Barone allgemein bezeichnet. Die Verteilung des landwirtschaftlichen Grundbesitzes vor dem Kriege ergibt sich aus der Tabelle 2 (S. 61).

Die Grundherren hielten an ihrem Besitz fest. Dem Bauern wurde selten oder nie die Möglichkeit gegeben, neues Land zu erwerben. Schon die Stolypinsche Landreform hatte eine Änderung dieser Verhältnisse für ganz Rußland in die Wege geleitet, und während der deutschen Okkupation erboten sich die baltischen Feudalherren freiwillig oder unter dem Druck unserer obersten Heeresleitung, $1 / 3$ ihres Besitzes für Siedlungszwecke abzutreten. Hierdurch war jedoch der Lauf der Dinge nicht aufzuhalten, und mit den ersten Atemzügen der neuen Republik wurde der Plan konzipiert, den Großgrundbesitz zu enteignen und aufzuteilen, also eine tiefgreifende Agrarreform durchzuführen, für ein so junges und an Barmitteln armes Land eine gewaltige Aufgabe. Über die Art der Aufteilung kann hier nur andeutungsweise gesprochen werden. Die Handhabung der Maßnahme ist besonderen Komitees anvertraut, die auf Grund des Agrargesetzes vom 24. September 1920 geschaffen worden und stufenartig aufgebaut sind. Das unterste ist das Gemeinde-Komitee; es besteht aus 5 Mitgliedern, die von den Gemeindeeingesessenen gewählt werden. Seine Aufgabe besteht in der Ausarbeitung von Vorschlägen und Anregungen zur Aufteilung und Nutzung des Landes und $\mathrm{Zu}$ weisung der neu eingeteilten Besitzungen an die sich hierum Bewerbenden. Über diese Komitees ist das Kreiskomitee gesetzt, bestehend aus 5 Regierungs- und 5 von den Kreiseingesessenen gewählten Mitgliedern. Es hat die Gemeindekomitees zu überwachen und Beschwerden gegen deren Beschlüsse zu entscheiden. Über den Kreiskomitees wiederum als oberste Behörde für die 
Landverteilung steht das Landeszentralkomitee; dieses wird aus 6 Regierungsvertretern und 6 Parlamentsmitgliedern gebildet. Ihm liegt es ob, die großen Richtlinien für die Durchführung der Landreform festzusetzen. Zugleich ist es die letzte Instanz für Beschwerden gegen die Entscheidungen der untergeordneten Komitees. Man beabsichtigt in Lettland nicht, das Land wahllos an jeden sich meldenden Bewerber zu verteilen, sondern bevorzugt werden Kriegsteilnehmer und solche Landarbeiter oder kleine Besitzer, die bereits einen gewissen Grundstock an Inventar besitzen. Die neuen Landstellen sollen in der Regel nicht größer als 22 ha sein, also mittlere Bauerngüter werden. Den früheren Grundherren wird ein Restgut von 50 bis 100 ha belassen. Privater Waldbesitz wird nicht aufgeteilt, sondern geht in den Besitz des Fiskus über, so daß, von geringen Ausnahmen abgesehen, der gesamte Waldbestand Lettlands Eigentum des Staates wird.

Zur wirtschaftlichen Durchführung der Agrarreform ist dị staatliche Agrarbank begründet worden; ihr Grundkapital beträgt 50 Millionen Rubel, daneben sind ihr beträchtliche Summen aus staatlichen Fonds zur Verfügung gestellt, so daß ihre Mittel insgesamt ungefähr 500 Millionen Rubel betragen. Der für die Landaufteilung ins Leben gerufene Exekutivapparat ist bereits in voller Tätigkeit. Der gesamte staatliche Landfonds beträgt ohne Einrechnung der Provinz Lettgallen ungefähr 2,5 Millionen ha. Hiervon waren bis zum 1. 1. 1922 annähernd $480000 \mathrm{ha}=20 \%$ zur Gründung von wirtschaftlichen Einheiten vergeben, und man hofft, bis zum Frühjahr des Jahres 192340000 neue Wirtschaften endgültig abgegrenzt und an die Aspiranten verteilt zu haben, was einer Fläche von 880000 ha entsprechen würde.

Natürlich wird es im wesentlichen eine Geldfrage sein, ob man die Maßnahme in ihrem ganzen, vom Gesetzgeber beabsichtigten Umfang wird in die Tat umsetzen können. Die hierbei zu überwindenden Hindernisse sind mannigfaltig; sie liegen zum Teil in der Schwierigkeit, unter der großen Anzahl der Landaspiranten die richtige Auswahl zu treffen, zum Teil im Mangel an Inventur, zum Teil an dem Fehlen von Wirtschafts- und Wohngebäuden für die neu abgegrenzten Besitzeinheiten. Letzterem Mangel will die Regierung dadurch abhelfen, daß sie Holz zum Aufführen von Blockhäusern den Neusiedlern aus den staatlichen Wäldern kostenlos zur Verfügung stellt, was allerdings auf der anderen Seite eine starke Belastung der Waldwirtschaft bedeuten würde.

Jedenfalls aber zeigen die obigen Ausfühirungen, daß die Agrarreform nicht nur eine theoretisch beschlossene Maßnahme 
bleibt, sondern daß energisch an ihrer Durchführung gearbeitet wird. Es darf die Erwartung ausgesprochen werden, daß die lettländische Regierung im Interesse ihres eigenen internationalen Ansehens die früheren Besitzer des Grund und Bodens in angemessener Weise entschädigen wird, denn erst dann wird die Landreform ihren Hauptzweck, innere Spannungen aufzuheben und Gegensätze auszugleichen, erfüllen.

Die Landaufteilung in Lettland hat die Aufmerksamkeit weiter Kreise in Europa auf sich gezogen und nicht ohne Grund. Solange es gefügte, in sich geschlossene Staatengebilde gibt, d. h. solange fundierter Reichtum einer besitzlosen Menge gegenübersteht, war zu allen Zeiten und bei allen Kultur-Völkern die Hauptursache aller sozialen Spannungen und Konflikte in der ungleichmäßigen Verteilung des Landbesitzes zu suchen.

Alle staatlichen Reformatoren seit den Zeiten der Antike haben an diesem Punkte den Hebel anzusetzen versucht, selten aber ist das Problem gelöst worden, denn es dürfte kaum ein wirtschaftliches Problem geben, das dem Staatsmann und Gesetzgeber größere Schwierigkeiten bereitet, keine Maßnahme, die größere Widerstände gegen ihn weckt, als der Versuch einer Neuregelung der Bodenbesitzverhältnisse.

Gewiß waren in Lettland die Vorbedingungen für die Reform insofern günstig, als die Eigentümer des Großgrundbesitzes jegliche politische Macht verloren hatten. Daß aber dennoch ein Land in der Lage Lettlands kurz nach seiner Gründung, mit äußeren und inneren Schwierigkeiten jeglicher Art kämpfend, sich an diese Aufgabe heranwagte und sie auch bisher erfolgreich durchgeführt hat, läßt den Schluß zu, daß die organisatorischen Fähigkeiten der lettischen Staatsmänner höchst bemerkenswerte sein müssen, und es gibt uns Veranlassung, mit verstärktem Interesse das Werden und die Entwicklung dieser neuen Republik zu beobachten.

Ich muß es mir leider im Rahmen der vorliegenden Arbeit versagen, noch näher auf die lettländische Agrarreform einzugehen, möchte jetzt vielmehr der Frage nähertreten, inwieweit die durch diese Maßnahme bewirkten Eingriffe in die bisherige landwirtschaftliche Produktionsweise auf die Ertragfähigkeit des Landes einzuwirken geeignet sind.

Von vielen Seiten ist die Ansicht ausgesprochen worden, daß die Depossedierung der Großgrundbesitzer zu einer Minderung der Getreideproduktion führen werde, denn einerseits sei es eine allgemein anerkannte Tatsache, daß Getreidebau nur vorteilhaft von 
Großbesitz betrieben werden könne, dann aber würden die neuen Siedler nicht genügend Sachkenntnis, Geldmittel und Fähigkeit für die Bewirtschaftung des Landes mitbringen. Man folgert hieraus, daß Lettland in Zukunft gezwungen sein werde, einen Teil seines Getreidebedarfs aus dem Auslande zu beziehen; die Schwächung der Landwirtschaft werde also auch die ungünstigsten Folgen auf die Finanzlage des Landes haben. Vor solch summarischen Aburteilungen soll gewarnt werden; sie werden den tatsächlichen Verbältnissen nicht gerecht.

Eine Getreide-Überschußwirtschaft - ein Überschuß für Exportzwecke - ist erfahrungsgemäß an Großbesitz gebunden. Der Gegenpol hierzu, der Kleinbauernbesitz, produziert höchstens so viel, wie er selbst in seinem Haushalt gebraucht. Die in Lettland neu zu parzellierenden Siedlungsgüter werden nun in der Mitte zwischen diesen beiden Außenpolen stehen; sie sollen so groß sein, daß nicht nur der Eigenbedarf des Besitzers gedeckt werden kann, sondern daß auch die Städte mit einheimischem Getreide versorgt werden können. Um zu gewährleisten, daß das Land sachgemäß bewirtschaftet wird, wird es nicht wahllos vergeben werden, sondern niemand hat Aussicht, ein Siedlungsgut zu erhalten, der nicht eine gute Kenntnis der Landwirtschaft nachweisen kann. Ferner aber ist wichtig für die Beurteilung der künftigen Produktion Lettlands, daß der Bauer intensiv wirtschaftet, der Großgrundbesitzer aber früher extensiv gewirtschaftet hat. Der Übergang von der extensiven zur intensiven Wirtschaft mag also sogar eine Erhöhung der Produktion mit sich bringen, um so mehr, wenn Hand in Hand mit der Umgestaltung des Grundbesitzes eine Verbesserung der Betriebsmittel geht. Letzteres scheint allerdings ein dringendes Erfordernis zu sein. Schon vor dem Kriege war das landwirtschaftliche Gerät, die Maschinen, der Menge nach unzureichend, das Vorhandene aber zum Teil veraltet und konnte den Anforderungen der modernen landwirtschaftlichen Technik nicht genügen. Man ist sich selbstverständlich auch in der Regierung der Bedeutung dieser Frage bewußt, und durch planmäßige Bereitstellung von Geldmitteln wird bereits daran gearbeitet, den Bestand an landwirtschaftlichem Gerät zu verbessern.

Die pessimistischen Prophezeiungen über die Zukunft der landwirtschaftlichen Produktion, die man allgemein im Jahre 1920 hörte, sind im gewissen Grade bereits durch das Ernteergebnis des Jahres 1921 widerlegt worden, und zwar werden die folgenden Ziffern für sich selbst sprechen: 
Es betrug der Ertrag einer Lofstelle an Roggen

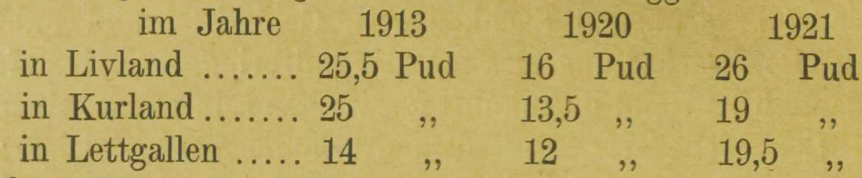

Im Jahre 1920 war durch die Nachwirkungen des Krieges und durch die Beunruhigung, die die nahende Agrarreform in die Kreise der Landwirte hineingetragen hatte, die Ernte zurückgegangen; daher mußte die Regierung, um den Bedarf der Bevölkerung zu decken, aus dem Ausland Getreide einführen. Diese Einfuhr konnte bereits im Sommer des Jahres 1921 wieder eingestellt werden, da die heimische Produktion inzwischen sich soweit erholt hatte, daß sie zur Versorgung der Bevölkerung ausreichte.

Die bemerkenswerte Steigerung des Ernteergebnisses von 1921 gegenüber dem des Vorjahres bei verhältnismäßig geringer Steigerung der Anbaufläche zeigt sich besonders klar in der nachfolgenden Übersicht.

\begin{tabular}{|c|c|c|c|c|c|c|c|c|}
\hline & \multicolumn{2}{|c|}{1913} & \multicolumn{2}{|c|}{1920} & \multicolumn{2}{|c|}{1921} & \multicolumn{2}{|c|}{1922} \\
\hline & $\begin{array}{c}\text { Bebaute } \\
\text { Fläche in } \\
1000 \text { ha }\end{array}$ & $\begin{array}{c}\text { Ernte- } \\
\text { ergeb- } \\
\text { nis in } \\
\text { Mill. } \\
\text { Pud }\end{array}$ & 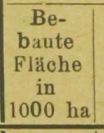 & $\begin{array}{c}\text { Ernte- } \\
\text { ergeb- } \\
\text { nis in } \\
\text { Mill. } \\
\text { Pud } \\
\end{array}$ & \begin{tabular}{|c|}
$\begin{array}{c}\text { Be- } \\
\text { baute } \\
\text { Fläehe } \\
\text { in } \\
1000 \mathrm{ha}\end{array}$ \\
\end{tabular} & $\begin{array}{l}\text { Ernte- } \\
\text { ergeb- } \\
\text { nis in } \\
\text { Mill. } \\
\text { Pud } \\
\end{array}$ & \begin{tabular}{|c|} 
Be- \\
baute \\
Fläche \\
in \\
$1000 \mathrm{ha}$
\end{tabular} & $\begin{array}{l}\text { Ernte- } \\
\text { ergeb- } \\
\text { nis in } \\
\text { Mill. } \\
\text { Pud } \\
\end{array}$ \\
\hline Roggen & 357 & 7,8 & 197 & 5,9 & 227 & 9,5 & & 8,9 \\
\hline Weizen & 34 & 0,8 & 16 & 0,45 & 19 & 0,98 & noch & 0,54 \\
\hline Hafer . & 317 & 6,8 & 216 & 4,7 & 252 & 10,0 & nicht & 9,6 \\
\hline Gerste. & 200 & 5,9 & 124 & 3,6 & 146 & 8,0 & be- & 8,5 \\
\hline Flachs & 67 & 0,75 & 30 & 0,6 & 34 & 0,6 & kannt & 0,6 \\
\hline Kartoffeln & 85 & 30,5 & 49 & 35,2 & 59 & 40,0 & & 40,8 \\
\hline
\end{tabular}

Es darf also als erwiesen gelten, daß die Agrarreform nicht notwendigerweise eine Verringerung der Getreideproduktion mit sich bringen muß. Unter den heute für Lettland geltenden besonderen Verhältnissen darf sogar das Gegenteil behauptet werden. Es herrscht nämlich in Lettland wie im gesamten Osten Mangel an künstlichen Düngemitteln, ohne die imlandwirtschaftlichen Großbetrieb der Getreidebau nicht aufrecht erhalten werden kann. Auch ist es nicht wahrscheinlich, daß in absehbarer Zeit diesem Mangel, der sich in ganz Mittel- und Osteuropa fühlbar macht, abgeholfen werden kann. Ein unaufgeteilter Großgrundbesitz würde hierdurch in seiner Produktionsfähigkeit mehr behindert werden als Kleinbesitz. Die Bauernwirtschaft produziert den Dünger, den sie benötigt, selbst; sie kann in größerem Maße als der Großgrundbesitz des künstlichen Düngers entraten. Es ist daher wahrscheinlich, 
daß unter den heutigen Verhältnissen in Lettland im Bauernbetriebe mehr, wenigstens aber ebenso viel Getreide produziert wird, als dieses bei unaufgeteiltem Großgrundbesitz der Fall sein würde.

Äbnliches darf für das zweitwichtigste landwirtschaftliche Anbauerzeugnis, den Flachs, in Anspruch genommen werden. Jedermann weiß, daß Flachs das eigentliche Produkt des Bauerngutes des Ostens ist; in Großbetrieben wird er wenig gepflanzt. Die Agrarreform ist also darauf berechnet, daß sie dazu beitragen wird, die Erzeugung des Flachses über das frühere Maß hinaus zu heben. Zahlen lassen sich hierfür noch nicht nennen, sie wären im wesentlichen heute noch theoretisch. Aber die Theorie ist gesund und begründet, und die Praxis wird ihre Richtigkeit beweisen.

Wenden wir uns nun zu dem landwirtschaftlicien Erzeugnis, das für den lettischen Außenhandel das Wichtigste ist, ich meine das Holz. Hierbei soll der Kürze wegen alles speziell Forsttechnische oder Handelstechnische ausgeschaltet werden, also alle Einzelheiten übergangen werden, die den Fachmann allein interessieren, und wir wollen uns auf das beschränken, was für die Wirtschaft im allgemeinen typisch oder wichtig ist, was also den Handelspolitiker interessiert.

Die Holzausfuhr aus Riga vor 1914 ergibt sich aus der nachfolgenden Tabelle 3 (S. 62).

Zunächst haben wir uns zu fragen, wie groß die Holzbestände Lettlands sind, da sich hieraus die Exportfähigkeit des Landes ableitet. Es ist eine ganz interessante Erscheinung und wirft ein Schlaglicht auf die Mangelhaftigkeit unserer wirtschaftlichen Informationsquellen, daß über diese fundamentale Frage weitgehende Meinungsverschiedenheiten bestehen. So habe ich in Lettland einen Herrn gesprochen, der als Waldtaxator mehrere Monate die lettischen Wälder untersucht hat. Dieser erklärte, daß die Waldbestände nicht erheblich seien und an einen größeren Export nicht gedacht werden könne. Zur selben Zeit wurde mir von einem mir seit langem als Fachmann und tüchtigen Geschäftsmann bekannten deutschen Holzindustriellen, der ebenfalls vor kurzem die lettischen Waldungen besichtigt hatte, versichert, daß bedeutende Bestände vorhanden seien und die Exportfähigkeit Lettlands günstig beurteilt werden müsse. Die offiziellen lettischen Statistiken sind natürlich ebenfalls optimistisch, die Presseäußerungen geteilt. Im Latvian Economist vom 1. April 1921 wird eine Berechnung eines deutschen Fachblattes abgedruckt; nach dieser könnte Lettland nach Deckung des Eigenbedarfs der Bevölkerung, der Verkehrsinstitutionen und der Industrie jährlich ungefähr 
24000000 Kubikfuß, d. i. $14 \%$ des jährlichen Zuwachses, exportieren. $\mathrm{Zu}$ einem anderen Ergebnis kommt die nicht veröffentlichte Denkschrift eines Rigaer Forstfachmannes, der schon vor vor dem Kriege als einer der besten Kenner der lettischen Wälder gegolten hat. Dieser nämlich kommt zu dem Schluß, daß nach Deckung des Eigenbedarfs überhaupt kein Überschuß für Exportzwecke vorhanden sei, falls nach forsttechnisch anerkannten Grundsätzen abgeholzt werde, d. h. falls man nicht vom Waldkapital leben, sondern unter Beobachtung und Zugrundelegung der üblichen Nachwuchsperioden einschlagen, mit anderen Worten, wenn man nicht Raubbau treiben wolle. Die Denkschrift führt aus, daß vor dem Kriege in großem Maße aus den lettischen Wäldern exportiert werden konnte, weil der Eigenbedarf der Bevölkerung zum größten Teil aus dem Holze gedeckt wurde, das im Transit aus dem heutigen Sowjetrußland kam und das in Riga oder den anderen lettischen Hafenstädten verarbeitet wurde. An Hand der von den Hafenbehörden und Börsenkomitees veröffentlichten amtlichen Zahlen wird ausgerechnet, daß von dem in lettischen Häfen verschifften Holz vor dem Kriege nur ungefähr $20 \%$ aus lettischen Wäldern stammte, alles übrige aus den anderen Provinzen Rußlands gekommen war. Insbesondere wurde auch der Brennholzbedarf der Bevölkerung fast gänzlich aus den Abfällen der lettischen Sägeindustrie gedeckt, die im wesentlichen außerlettisches. Holz verarbeitete. Jetzt dagegen sei Lettland auf seine eigenen Holzquellen angewiesen. Aber nicht nur dies: der Eigenbedarf sei auch gegenüber der Vorkriegszeit erheblich gestiegen, und zwar einmal infolge der Notwendigkeit, das durch den Krieg Verwüstete wieder herzustellen - ungefähr $10 \%$ aller Baulichkeiten in Lettland sind zerstört - und ferner durch die Agrarreform, durch die vorgesehen sei, innerhalb der nächsten 4 Jahre auf den neuen Siedlungsgütern 100000 Gebäude aus Holz aufzuführen. Nichtsdestoweniger aber faßt der Verfasser schließlich seine Ausführungen doch dahin zusammen, daß im Interesse des Gleichgewichts der gesamten Wirtschaft es erforderlich sei, $\mathrm{Holz}$ zu exportieren, ja, er rät sogar, einen Teil des Waldvermögens des Staates in werbendes Kapital zu verwandeln, d. h. die Waldbestände zu verringern und den Erlös für werbende Anlagen zu verwenden. Er weist in seinen eingehenden Ausführungen darauf hin, daß der lettische Waldbesitz, dessen Wert er insgesamt auf 550 Millionen Goldrubel schätzt, so wertvoll sei, daß3 eine derartige Umwandlung möglich sei, ohne die Forstwirtschaft dadurch $\mathrm{zu}$ gefährden oder dauernd $\mathrm{zu}$ schwächen. 
Als Endergebnis aller Überlegungen auf Grund des vorliegenden Materials kommt man also trotz mancher gegenteiliger Äußerungen doch zu dem Schluß, daß auch in Zukunft ein erheblicher Holzexport aus Lettland stattfinden wird, ohne daß hieraus eine Verschlechterung des lettischen Nationalvermögens abzuleiten wäre.

Was nun die Holzbewirtschaftung anlangt, so ist bereits erwähnt worden, daß, von einem kleinen Bruchteil abgesehen, die Waldungen Staatsbesitz geworden sind. Ob dieses ein Vorteil für die Forstwirtschaft ist oder ein Nachteil, darüber wäre ein Urteil wohl verfrüht. Als bekannt wird auch in der von mir erwähnten Denkschrift vorausgesetzt und zahlenmäßig bewiesen, daß die Großgrundbesitzer in den letzten Jahren mit ihren Waldungen Raubbau getrieben haben und in Nachpflanzungen säumig gewesen sind. Ob der lettische Staat und das ihm zur Verfügung stehende Beamtenpersonal besser wirtschaften wird, das wird sich erst zu erweisen haben; eine Minderung des Holzanfalles für die Zukunft zu erwarten, wäre aber vorläufig ungerechtfertigt.

Aus den vorstehenden Erwägungen über Lettland als Agrarland und Rohstofflieferanten hat sich ergeben, daß, gleichgültig, ob die Agrarreform in ihrem ganzen beabsichtigten Umfange oder nur teilweise durchgeführt werden kann, diese Maßnahme die Produktionsfähigkeit Lettlands nicht verringern wird, daß im Gegenteil durch sie wahrscheinlich die Flachsausbeute gesteigert werden wird und die Ausfuhr von Holz und Flachs auch in Zukunft gesichert erscheint.

\section{Die Industrie Lettlands.}

Wir wenden uns nunmehr zur Betrachtung der Industrie, des dritten Gebietes, auf dem sich die lettländische Volkswirtschaft betätigt hat.

Die lettländische Industrie vor dem Kriege, die sich im wesentlichen in Riga und Libau konzentrierte, war nicht unerheblich. In Riga wurden nach einer Statistik des Börsenkomitees in $372 \mathrm{Be}-$ trieben 87606 Arbeiter beschäftigt. Der größte Betrieb war der der Gummifabrik Prowodnik, der 15000 Arbeitern und Angestellten Tätigkeit gab, dann kam die Russisch-Baltische Waggonfabrik mit bis zu 4000 Arbeitern und die Waggon- und Maschinenfabrik Phönix, die bei guter Geschäftslage bis zu 3000 Arbeiter beschäftigte. Insgesamt waren im Maschinenbau und den verwandten Branchen in 49 Betrieben ungefähr 20300 Arbeiter tätig, die Textilindustrie beschäftigte in 18 Betrieben gegen 10300 Menschen, die Holz- 
industrie ungefähr 7800. In der Libauer Industrie waren schätzungsweise an 4500 Arbeiter tätig.

Von der Rigaer Industrie des Jahres 1914 ist wenig übriggeblieben; ihr Untergang ist zwar eine Folge des Krieges, nicht aber unmittelbar feindlicher Einwirkung zuzuschreiben; als nämlich im Sommer 1915 sich unsere Armee auf ihrem Vormarsch im Osten mehr und mehr der Stadt Riga näherte und mit deren Fall in kürzester Zeit gerechnet werden mußte, entschied die russische Heeresleitung, daß der wertvolle Industriebesitz nicht in die Hände des Feindes fallen dürfe; infolgedessen wurde verfügt, daß die Industrie aus Riga zu transplantieren und im Innern Rußlands wieder aufzubauen sei. Ohne daß man noch recht wußte, an welchen Orten der Wiederaufbau vor sich gehen werde, wurden daraufhin die Maschinen und Kraftanlagen aus den Fabriken herausgebrochen und auf Eisenbahnwaggons geladen; in wenigen Wochen sind so 60000 Waggonladungen aus Riga fortgeführt worden. Z Zu einem geordneten Transport und Wiederaufbau ist es nicht gekommen; die wenigsten Sendungen haben einen neuen Verwendungsort erreicht; denn da gerade um diese Zeit plötzlich infolge der kriegerischen Ereignisse alle verfügbaren Transportmittel für militärische Operationszwecke herangezogen werden mußten, wurden die Waggons auf der Strecke angehalten und die Ladung abgesetzt, wo sie gerade stand, kurz, die Maschinen, der Produktionsapparat der bis dahin blühenden Rigaer Industrie, wurden über das ganze Reich verstreut, sie sind verdorben, vernichtet, gestohlen. In dem zwischen der Sowjetrepublik und Lettland geschlossenen Friedensvertrag vom 11. August 1920 hat sich die erstere zwar verpflichtet, die noch vorhandenen Maschinen zu reevakuieren, $d$. h. sie wieder auszuliefern. Lettländische Herren, die gut orientiert sein müssen, haben aber erklärt, daß sie dieser Vereinbarung wenig realen Wert für Lettland beimessen, da nicht mehr viel vorhanden sei und das wenige Übriggebliebene schwer greifbar sein dürfte. Bis Mitte des Jahres 1921 waren erst gegen 120 Waggonladungen nach Lettland zurückgeführt worden, die seither angelieferten Mengen sind noch geringer. Zugleich mit den Maschinen wurden im Jahre 191570000 Industriearbeiter mit ihren Familien in das Innere Rußlands umgesiedelt. Es ist dies wohl der Grund dafür, daß man zurzeit in Riga kein Arbeiterproletariat sieht, aber auch dafür, daß die Stadt fast die Hälfte ihrer Einwohner verloren hat und ganze Viertel verlassen sind.

Die Rigaer Industrie müßte also, soll sie wieder entstehen, fast von Grund auf neu aufgebaut werden, und es wird später die 
folgenschwere Frage zu erörtern sein, ob sich deutsches Kapital und deutsche Unternehmerarbeit an diesem Wiederaufbau beteiligen will, soll oder muß. Zunächst aber ist es erforderlich, sich die Grundlagen und Bedingungen klarzumachen, auf denen die Industrie vor dem Kriege beruhte, mit anderen Worten zu ihrer „raison d'être" zu gelangen.

Vielfach ist behauptet worden, daß sie eine Treibhauspflanze gewesen sei, ein künstliches Produkt, gezüchtet durch das Mittel des russischen Schutzzolltarifes. Daß sie künstlich gewesen sei, gehe schon daraus hervor, daß sie fast ihre gesamten Rohstoffe und Betriebsmittel von auswärts habe beziehen müssen, so daß beispielsweise jedes Kilogramm Kohle, das sie brauchte, aus England importiert worden sei. Die Tatsachen sind richtig, nicht aber die daraus gezogenen Schlüsse; denn mit diesen Argumenten kann man einer Industrie nicht beikommen; man gelangt mit ihnen nicht heran an die Wurzeln, auf denen sie ruht, aus denen sie ihre Kraft und ihren Lebenssaft saugt.

Die eigentliche Schutzzollperiode des zaristischen Regimes beginnt mit dem Zusatzvertrag des Jahres $1904 \mathrm{zu}$ dem deutschrussischen Handelsvertrag von 1894. Dieser Zusatzvertrag, der die Einfuhrzölle für eine Reihe von Fertigfabrikaten erheblich erhöhte, trat im Jahre 1906 in Kraft. Daß von ihm auch die Rigaer Werke Nutzen zogen, geht aus der Betriebsstatistik gemäß Tabelle 4 (S. 62) hervor. Die Zahl der Fabrikarbeiter, die seit dem Jahre 1901 ständig zurückgegangen war, beginnt also plötzlich im Jahre 1906 zu steigen und ist bereits im nächsten Jahre sprungartig um $25 \%$ angeachsen, auf welcher Höhe sie sich dann bis 1914 mehr oder minder behauptet hat. Aber hat nicht auch Deutschland Schutzzölle für seine Fabrikerzeugnisse gehabt, und ebenso Frankreich, Belgien und die Vereinigten Staaten? Hat nicht ein jedes Land seine Industrie mit Hilfe von Schutzzöllen aufgebaut und stark gemacht, ja, haben nicht manche Länder sogar ihre Industrien nur dadurch dauernd erhalten können, daß sie sie mit einem Schutzzollwall umgaben? Aus diesem Grunde nennen wir aber im allgemeinen solche Industrien nicht künstliche oder Treibhauspflanzen, und wir tun es auch dann nicht, wenn die konsumierten Rohstoffe und Betriebsmittel im eigenen Lande nicht oder nur zum geringen Teil vorhanden sind, sondern aus dem Ausland bezogen werden müssen. Belgien hat, wie schon erwähnt worden ist, $35 \%$ seines Kohlenbedarfs aus dem Auslande eingeführt, und zwar zum Teil aus England, und um auf Deutschland zurückzugreifen, so darf an die ziemlich umfangreiche Industrie in Hamburg erinnert werden, die 
ausschließlich englische Kohle verbrennt. Mehr noch: es ist ja allgemein bekannt, daß auch im Herzen von Deutschland, in Berlin, große Mengen englischer Kohle für industrielle Zwecke Verwendung fanden und heute wieder finden. Mit den angeführten Argumenten der Rigaer Industrie die „raison d'être" abzusprechen, dürfte daher wohl nicht angängig sein; in dieser summarischen Weise können wir nicht eine Frage abtun, die für unsere politische und wirtschaftliche Geltung im Osten solch weittragende Bedeutung besitzt.

Die Tatsache, daß in Lettland, der Provinz des Zarenreiches, die intellektuelle Klasse, die Oberschicht der Erwerbskreise, deutsch oder deutschstämmig war, war einer der Gründe für das Gedeihen der Rigaer Fabriken. Denn es war damit ein Element vorhanden, das eine höhere industrielle und kaufmännische Begabung, zugleich auch eine größere wirtschaftliche Aktivität besaß als der Russe. Vielleicht - und wenn man sich in ihre Entstehungsgeschichte vertieft, möchte man es glauben - war dies überhaupt der äußere Ausgangspunkt der Rigaer Industrie. Zugleich bestimmte dieses Moment einen ihrer Charakterzüge; denn $\mathrm{da} ß$ die Rigaer Werke im russischen Reich sich den Ruf einer Qualitätsindustrie erworben hatten, ihre Fabrikate als Qualitätsware höher bezahlt wurden als gleiche Waren anderer russischer Herkunft, ist gewiß allein der Tatsache zuzuschreiben, daß sie deutsche Ingenieure, Techniker und Werkmeister beschäftigten. Die regen persönlichen Verbindungen der Deutsch-Balten mit Deutschland schufen ferner einen engen Konnex zwischen den leitenden Persönlichkeiten der beiderseitigen Industrien, ließen also den Rigaer Fabriken die technischen und organisatorischen Fortschritte und Erfahrungen der deutschen Werke in hohem Maße zugute kommen. Suchen wir aber die im engeren Sinne wirtschaftlichen Grundlagen, den Ausgangspunkt, von dem aus die Industrie in Riga erwuchs und sich organisch weiterentwickelte, so werden wir solchen in der geographischen Lage der Stadt finden. Gerade in diesem Punkte zeigt sich die Parallelität mit den Verhältnissen in Belgien: weil nämlich Riga, der Stapelplatz und Ausfuhrhafen der russischen Erzeugnisse, ein Zentralpunkt der Schiffahrt im Osten geworden war, konnte es dank seines Schiffsverkehrs die ausländischen Rohstoffe und Betriebsmittel zu günstigen Frachten beziehen. Die Schiffe, die die russischen Erzeugnisse nach dem Ausland führen sollten, gewährten, um nicht mit Ballast nach Riga zu fahren, billige Tarife für Verfrachtungen dorthin, und so konnten die Rigaer Fabriken entstehen und florieren, wenngleich sie auch jedes Kilogramm Kohle, das in ihren Kesseln brannte, aus England bezogen. Nach einer 
Statistik des Rigaer Börsenkomitees war ungefähr 50 \% aller eingeführten Ware für die Versorgung der Industrie bestimmt. Selbstverständlich waren das Vorhandensein gewisser Rohstoffe, so insbesondere des Holzes, und die Tatsache, daß die Lebenshaltung der unteren Klassen in Rußland gering und die Löhne daher billig waren, zwei weitere Ursachen für das Aufblühen der Rigaer Fabriken, deren Bedeutung am besten daraus erhellt, daß sie im Jahre 1913 für annähernd 475 Millionen Goldmark Waren erzeugten, das ist ungefähr $8 \%$ der gesamten deutschen Ausfuhr von Fertigerzeugnissen desselben Jahres.

Oberste Voraussetzung aber für ihr Bestehen war das Vorhandensein eines Absatzgebietes, war der Bedarf des russischen Reiches, für den allein die Rigaer Werke zugeschnitten und eingerichtet waren. Bei diesem Punkte hört die Übereinstimmung mit Belgien auf; denn die belgische Industrie war auf den Export gegründet, ihr Absatzgebiet war die ganze Erde, einige Zweige exportierten bis zu $90 \%$ ihrer Gesamtproduktion. Die Rigaer Fabriken dagegen verkauften nur ganz unerhebliche Mengen ins Ausland, ihr einzig großes Absatzgebiet war die Heimat, das Zarenreich. Hier nun liegt die eigentliche Schwierigkeit in der Frage, ob wir uns an dem Wiederaufbau der Industrie beteiligen sollen; denn Lettland und die Randstaaten allein würden kein genügend großes Absatzgebiet sein, um die Rigaer Werke in ihrem früheren Umfange auch nur für wenige Monate im Jahre zu beschäftigen. Rußland dagegen ist vorläufig als Abnehmer fortgefallen, und niemand kann heute wissen, wann seine Kaufkraft wieder erstarken wird. Auch weiß man noch nicht, welche Zollpolitik Sowjetrußland in Zukunft gegenüber Lettland einschlagen wird, ob es Industriezölle einführen und sie auch gegen lettische Produkte erheben wird. In letzter Zeit ist nun allerdings von russischer Seite ein Schritt getan worden, der einen Lichtblick auf unser Bild wirft. Die russische Regierung hat nämlich durch eine Verordnung bestimmt, daß Industrieerzeugnisse, soweit sie in Lettland mit einheimischer Arbeit und einheimischem Rohmaterial hergestellt sind, zollfrei nach Sowjetrußland eingeführt werden sollen; für diese Erzeugnisse ist also die Zollgrenze vorläufig beseitigt worden. Dieser Tatsache aber allzu viel Bedeutung beizumessen, dürfte nicht ratsam sein, denn es handelt sich hierbei nicht um eine durch Staatsvertrag zwischen Rußland und Lettland festgelegte, also für Lettland rechtlich gesicherte Maßnahme, sondern um eine Verordnung, die einseitig und autonom von der russischen Regierung erlassen worden ist, aus Erwägungen, deren wahre Natur wir nicht kennen, 
und es ergibt sich hieraus von selbst, daß Rußland diese Maßnahme jederzeit auch wieder autonom zurückziehen $\mathrm{kann}^{1}$ ).

Da die Zukunft der Rigaer Industrie von Rußland abhängen wird, begrüßte ich die Gelegenheit, die sich in Riga bot, mit einem der Leiter der russischen Politik über diese Frage zu sprechen. Ich fragte ihn, wie sich seine Regierung zu der Wiederaufrichtung der lettischen Industrie stelle; es sei doch vielleicht nicht unwahrscheinlich, daß die Sowjetregierung bei den zerrütteten Fabrikationsverhältnissen in Rußland ein Interesse daran habe, daß in unmittelbarer Nähe ihrer Grenzen eine Industrie bestehe, die in der Lage sei, dann einzuspringen, wenn man der Eile wegen oder aus sonstigen Gründen nicht auf westliche Werke zurückgreifen wolle oder könne, so z. B. für eilige Reparaturen von Lokomotiven, für Lieferung von Eisenbahnmaterial und sonstigem öffentlichen Bedarf. Die Tatsache des Bestehens einer solchen Industrie in Lettland könne unter Umständen von großer wirtschaftlicher, vielleicht auch militärischer Bedeutung für Sowjetrußland sein. Würde also die Sowjetregierung die Wiederaufrichtung der lettischen Industrie tätig fördern? Für diese Gesichtspunkte hatte der betreffende Herr wenig Anerkennung. Er sagte, seine Regierung gäbe ihre Aufträge dem Billigsten. Würde Lettland günstigere Angebote machen als die, westeuropäischen Konkurrenten, dann würde man ihm Aufträge geben. Es mag allerdings dahingestellt bleiben, ob Moskau diesen Standpunkt auch heute noch aufrechterhält; die vorhin erwähnte Verordnung, die lettischen Waren Zollfreiheit gewährt, spricht dagegen. Vorläufig aber bleibt der Schleier ungelüftet; und wenn ich auch glaube, daß die dargelegten natürlichen Wurzelpunkte der Rigaer Industrie auch heute noch bestehen und daß die geographische Lage und die daraus bedingten Verhältnisse zu irgendeiner Zeit wieder fast zwangsläufig eine Industrie in Riga erstehen lassen werden, so sind doch offensichtlich durch die staatlichen Umwälzungen solch eingreifende Veränderungen geschaffen worden, daß die unmittelbare Zukunft der dritten volkswirtschaftlichen Funktion Lettlands, nämlich der industriellen, heute noch dunkel und unübersehbar ist.

1) Seitdem das Obige geschrieben worden ist, hat die Sowjetregierung die erwähnte Verfügung tatsächlich wieder außer Kraft gesetzt; allerdings ist Aussicht vorhanden, daß bei den bevorstehenden Handelsvertragsverhandlungen zwischen Rußland und Lettland eine endgültige dauerhafte Regelung erfolgen wird. 


\section{Politische Verfassung Lettlands.}

Die vorerwähnten ökonomischen Grundtatsachen ergeben die eine Seite des Bildes, das ich von Lettland vermitteln möchte, die andere Seite wird dargestellt durch die politischen und wirtschaftlichen Zustände der Gegenwart, auf die nunmehr eingegangen werden soll.

Die lettische Republik hat eine demokratische Verfassung. An der Spitze des Staates steht ein vom Parlament gewählter Präsident. Die politische und administrative Führung liegt in der Hand des Ministerpräsidenten und seines Kabinetts; jedoch macht sich häufig eine starke Abhängigkeit der Minister von der Volksvertretung auch in Einzelfragen bemerkbar, die oft der reibungslosen Erledigung der Geschäfte hinderlich ist. Das Parlament besteht aus 100 Mitgliedern, und zwar sind die einzelnen Parteien seit den letzten Wahlen in folgender Stärke vertreten:

$\begin{array}{lccc}\text { Sozialisten } & \text { mit } 36 & \text { Stimmen } \\ \text { Bauernbund } & " & 17 & , \\ \text { Minoritäten } & , & 17 & " \\ \text { Lettgallische Partei } & , & 12 & , \\ \text { Zentrum u. Jungwirte } & , & 10 & , \\ \text { Sonstige } & , & 8 & ,\end{array}$

Der erste Ministerpräsident, Herr Ullmann, war eine starke Persönlichkeit. Man kann ihn den Begründer der lettländischen Republik nennen. Als er im Frühjahr des Jahres 1921 aus innerpolitischen Gründen zurücktrat, trat an seine Stelle der bisherige Außenminister in seinem Kabinett, Herr Meyerowitz, eine noch jugendliche Erscheinung, sehr gewandt in seinem Auftreten und von großer Zuvorkommenheit. Ullmann fiel, weil er bei der Auflösung des Großgrundbesitzes nicht mit der von der Mehrheit des Parlaments gewünschten Schärfe vorgehen, eine extremsozialistische Agrarpolitik nicht mitmachen wollte. Es wäre folgerichtig gewesen, daß bei seinem Abgang ein Agrarsozialist die Regierung hätte bilden müssen. Man fühlte aber, daß das Erscheinen einer rein sozialistischen Regierung ein neuer Antrieb für die bolschewistischen Tendenzen sein würde, die im Volke durch die Nachbarschaft der Sowjetrepublik ständig genährt, allerdings jetzt mit starker Hand niedergehalten werden. Meyerowitz nun suchte die Schwierigkeiten der Lage dadurch zu überkommen, daß er ein Kabinett auf nationalistischer Grundlage gründete, in dem sämtliche Bürgerliche und auch die agrar-sozialistischen Parteien vereinigt waren. Diese heterogenen Elemente wurden also 
geeinigt unter einer lettländisch-nationalistischen Politik, unter der Devise: Lettland durch Lettländer für die Lettländer. Durch dieses Programm war der Regierung die Bahn vorgeschrieben, auf der sie zu wandeln habe; sie war durch ihr Programm sowohl für ihre auswärtige wie für ihre Wirtschaftspolitik gebunden. Dieses trat sogleich bei den bekannten Tilden-Smith-Verhandlungen in Erscheinung. Man hatte fast 2 Jahre mit einem englischen Konsortium über ein Monopol für die Ausnutzung der lettischen Forsten verhandelt; das Konsortium sollte als Gegenleistung bedeutende Geldmittel zum Aufbau einer holzverarbeitenden Industrie, zur Verbesserung der Verkehrswege, zur Errichtung einer Emissionsbank, kurz für werbende volkswirtschaftliche Zwecke zur Verfügung stellen. Diese Verhandlungen scheiterten unter dem neuen Kabinett kurz nach dessen Erscheinen aus dem Grunde, weil ihre Verwirklichung den Fremden eine zu große Macht in Lettland eingeräumt hätte.

Durch die Einigung auf einer nationalistischen Grundlage hat man die bolschewistische Bewegung tiefgehalten, ihr den Wind aus den Segeln genommen. Dieses werden als einen Gewinn buchen jene Kreise bei uns und im anderen Ausland, die sich durch Befürchtungen über drohenden inneren Bolschewismus von wirtschaftlicher Betätigung in Lettland haben zurückhalten lassen. Im Verlauf unserer Unterhandlungen habe ich die Erfahrung gemacht, daß die lettländische Regierung die Unterdrückung des Bolschewismus niemals außer acht läßt und auch jede wirtschaftliche Maßnahme unter diesem Gesichtspunkt prüft. Inzwischen haben die inneren politischenVerhältnisse übrigens eine solche Festigkeit gewonnen, daß an eine Ablösung der heutigen Regierungsform durch eine bolschewistische Gewalt ernstlich nicht mehr gedacht zu werden braucht.

Die lettländische Regierung hat also die Staatsgewalt fest in Händen, und sie handhabt sie innenpolitisch mit Energie, ohne doch zu Gewaltmaßnahmen zu greifen. Aber auch das andere Extrem, in das junge demokratische Staaten nach Beseitigung einer lange angestammten Obrigkeitsregierung so leicht verfallen, nämlich daß die demokratische Regierungsform zu einer Übertreibung der vermeintlichen Volksautorität, zur innerpolitischen Anarchie, führt, ist vermieden worden. Recht augenfällig tritt übrigens in Lettland das Instrument der Staatsgewalt, das Militär, in Erscheinung, ja, man möchte sagen, das öffentliche Leben trage den Stempel eines zwar noch jugendlichen, aber organisch gesunden Militarismus. Ich hatte Gelegenheit, den Empfang des Ministerpräsidenten bei einem Besuche in Libau zu beobachten. Auf dem 
Bahnhof war eine Ehrenkompagnie mit Militärkapelle aufgezogen. Der Ministerpräsident wurde zunächst von den Militärs begrüßt, dann erst wurden ihm die Zivilwürdenträger vorgestellt. Es folgte Abschreiten der Front der Ehrenkompagnie und Vorbeimarsch. Auch bei seinem öffentlichen Erscheinen in der Stadt war der Ministerpräsident stets von Militär umgeben.

Was die außenpolitischen Beziehungen Lettlands anbelangt, so ist natürlich sein Verhältnis zu Sowjetrußland von besonderer Bedeutung. Im Jahre 1920 ist zwischen Rußland und Lettland ein sogenannter Friedensvertrag abgeschlossen worden, zu einer Zeit, als die Sowjetrepublik sich durch ihre Verwicklungen mit Polen politisch im Nachteil befand. Dieser Vertrag war günstig für Lettland; Rußland trat ihm einen Waldkomplex von ungefähr 100000 ha ab und verpflichtete sich zur Rückgabe alles während des Krieges aus dem beutigen lettländischen Staatsgebiet weggeführten Besitzes. Ein freundschaftliches Verhältnis wurde durch diesen Vertrag nicht inauguriert; man wird vielmehr nicht fehl gehen, wenn man die gegenwärtigen Beziehungen zwischen Sowjetrußland und Lettland als korrekt, aber kalt bezeichnet. Beide Regierungen haben mancherlei konkrete Differenzpunkte. Der tiefere Grund für die herrschende Spannung liegt aber wohl darin, daß sie bedingt ist durch die geschichtliche Entwicklung der letzten Jahre. Lettland, die kleine Grenzprovinz, hat sich in der schwersten Zeit der russischen Nation vom Mutterlande getrennt; lebt also unter dem Gefühl der Befürchtung, daß das große Russenreich doch wieder seine Herrschaft über die junge Republik ausdehnen wird; die russische Nation aber sieht in dem lettischen Volk den Abtrünnigen von der gemeinsamen großen russischen Sache, und es ist innerlich entschlossen, ihm seinen Abfall nicht zu verzeiben.

Auf ökonomischem Gebiet hat sich diese Spannung mehrfach zur Geltung gebracht; eine ihrer Folgen war es, daß die Sowjetregierung lange Zeit versucht hat, wie oben erwähnt worden ist, den Hafen von Riga zu boykottieren und den Warenverkehr über Reval und Petersburg zu leiten. Man hat in Riga dieser offen erklärten Politik immer mit Ruhe begegnet, denn man hat von Anfang an darauf gerechnet, daß die ökonomischen Grundtatsachen stärker sein würden als politische Konstruktionen und daß der Warenverkehr notwendigerweise in die Bahnen gleiten würde, die seine natürlichen sind. Die Entwicklung des letzten Jahres hat dieser Ansicht recht gegeben. Heute bereits hat sich der Transitverkehr zwischen Riga und Rußland im Verhältnis zu demjenigen von Reval und Rußland erheblich gesteigert, und man dürfte nicht 
fehlgehen in der Erwartung, daß die Maienblüte Revals bereits ihr Ende erreicht und Riga in schneller Entwicklung auf und daran ist, seine alte geschichtlich gewordene Bedeutung für den russischen Warenverkehr wiederzugewinnen ${ }^{1}$ ).

Seit langem schweben Verhandlungen zwischen den baltischen Randstaaten, die einen engen politischen und wirtschaftlichen Zusammenschluß untereinander zum Ziele haben; auch Finnland hat sich hieran beteiligt. Verschiedene gemeinsame Konferenzen sind jedoch resultatlos verlaufen, und auch bei darauf einsetzenden Einzelverhandlungen zwischen Staat und Staat sind bisher keine Ergebnisse grundsätzlicher Art erzielt worden. Gelänge es dem Baltikum, eine militärische Konvention zu schließen, so würde dadurch im Osten ein neuer Machtfaktor geschaffen werden, über den nicht hinwegzusehen wäre, und mit dem die östlichen Großmächte zu rechnen hätten.

Uns dürfte gegenwärtig mehr interessieren, welche Folgen ein wirtschaftlicher Zusammenschluß, z. B. eine baltische Zollunion, für unseren Handel hätte. Hier dürfte kein Zweifel bestehen, und die Sachverständigen sind im allgemeinen darin einig, daß uns Nachteile daraus nicht erwachsen würden. Welche Form auch immer eine Wirtschaftsunion annehmen, welche Bedingungen im einzelnen sie schaffen würde, es ist durchaus wahrscheinlich, daß dadurch weder die Einfuhr deutscher Erzeugnisse ins Baltikum,

1) Das starke Anwachsen des Verkehrs zwischen Riga und Rußland zeigen die nachstehenden Ziffern. Die Lücken in der Zahlenreihe bedeuten, daß amtliche Ziffern für die fraglichen Zeiträume noch nicht zusammengestellt sind.

Lettlands Eisenbahnverkehr mit RuBland in tons $(1000 \mathrm{~kg})$.

\begin{tabular}{l|r|r|r|r}
\hline \hline & \multicolumn{2}{|c|}{ nach Rußland } & \multicolumn{2}{|c}{ von Rußland } \\
& 1921 & 1922 & 1921 & 1922 \\
\hline Januar..... & - & 21600 & - & 2400 \\
Februar.... & - & 22900 & - & 860 \\
März...... & - & 50600 & - & 1600 \\
April....... & 8000 & 69900 & - & 3400 \\
Mai....... & 4500 & 84400 & - & 3900 \\
Juni....... & 400 & 26900 & - & 2200 \\
Juli....... & 100 & 13200 & - & 1600 \\
August..... & 2900 & 8000 & 1600 & 1500 \\
September.. & 20000 & 3900 & 200 & 5100 \\
Oktober.... & 9900 & - & 500 & - \\
November... & 9700 & - & 1400 & - \\
Dezember... & 19200 & - & 4100 & - \\
& & & &
\end{tabular}


noch die Ausfuhr von dessen Rohstoffen nach Deutschland, noch die Bedingungen, unter denen Deutsche sich dort niederlassen und betätigen können, geschmälert werden würden. Man darf sogar weitergehen und behaupten, daß wenn eine Wirtschafts- oder Zollvereinigung der Randstaaten zustande käme, dieses eine Stabilisierung ihrer Wirtschaft zur Folge haben würde, ein Moment, das von uns begrüßt werden würde. Ich zweifle aber, ob der $\mathrm{Zu-}$ sammenschluß gelingen wird. Die wirtschaftliche Struktur in einem jeden der drei Staaten ist von Grund auf verschieden, und es ist daher unwahrscheinlich, daß sich aus ihnen eine wirtschaftliche Einheit wird schaffen lassen, ohne daß dadurch Lebensinteressen des einen oder anderen Staates auf das Spiel gesetzt werden.

Die Beziehungen Lettlands zu den westlichen Mächten sind klare. Es sind Verhandlungen im Gange mit Frankreich, England, Italien und einigen anderen Staaten über den Abschluß von Wirtschaftsverträgen, mit einigen Regierungen sind bereits Verträge zustande gekommen und besonders Frankreich legt Wert darauf, bei jeder Gelegenheit sein Wohlwollen für den jungen Staat öffentlich $\mathrm{zu}$ betonen.

Das Verhältnis zwischen Deutschland und Lettland ist leider ein nicht so klares und ungetrübtes, wie es die Höflichkeit der Diplomaten darzustellen bereit ist. Wie schon eingangs erwähnt worden ist, wurde am 15. Juli 1920 ein Vertrag geschlossen und von beiden Parlamenten ratifiziert, der drei Hauptbestimmungen enthält:

In $\S 5$ verpflichtet sich die deutsche Regierung, Lettland alle Schäden zu vergüten, die infolge des Krieges auf lettischem Boden entstanden sind;

in $\S 7$ verpflichtet sich die deutsche Regierung, sich dafür einzusetzen, daß Lettland ein Warenkredit gewährt werde;

in $\S 9$ kommen beide Parteien überein, alle ausstehenden wirtschaftlichen Fragen der Regelung durch Sonderkommissionen zu überlassen, die nach Bedarf in Berlin oder Riga tagen sollen.

In Durchführung der $\S \S 7$ und 9 ist dann im Juli 1921 die eingangs von mir erwähnte Kommission nach Riga gefahren; es kam dort ein Vertragsentwurf zustande, der von den Verhandlungsteilnehmern unterzeichnet und noch vor der Abreise der deutschen Kommission aus Riga die Genehmigung des lettländischen Kabinetts erhielt. In Ausführung einer vorherigen Vereinbarung, wonach die endgültige Vollziehung eines etwaigen Vertragsentwurfs in Berlin stattfinden solle, kam dann eine lettländische Kommission im 
Januar 1922 nach Berlin und hier fand nach langwierigen neuen Besprechungen am 23. März 1922 die Unterzeichnung statt. Bei den Rigaer Verhandlungen waren unsere Bewegungsgrenzen von vornherein durch die Umstände gegebene und eingeengte. Einerseits waren wir gehemmt durch den bekannten Art. 267 des Versailler Vertrags, demzufolge jede Vergünstigung, die Deutschland einem Staate einräumt, automatisch den gesamten Ententestaaten zugute kommt. Wirtschaftliche Reibungspunkte, wie sie gegenwärtig zwischen Deutschland und Polen bestehen, waren zwischen Deutschland und Lettland nicht vorhanden, es konnte sich also nur darum handeln, die vorhandenen wirtschaftlichen Beziehungen auszubauen und zu erweitern. Hierzu aber hätten wir, um empfangen zu können, auch geben müssen, wozu wir unter dem Versailler Vertrag nicht in der Lage waren. Hinzu kam, daß auch nicht durch etwaige Zollvereinbarungen eine Erweiterung unserer gegenseitigen Wirtschaftsbeziehungen herbeigeführt werden konnte. Dieser Fragenkomplex war ausgeschaltet, weil die deutsche Regierung ihre Zollpolitik, die sie einheitlich nach allen Richtungen hin handhaben will, nicht eher festlegen kann, als bis die Vorarbeiten für den neuen Zolltarif beendigt sind. Schließlich kam die nationalistische Tendenz des lettländischen Ministeriums in Betracht, die jeden Gedanken an die Erteilung von Wirtschaftskonzessionen von vornherein ausschlob, welche nach unserer damaligen Beurteilung der lettländischen Verhältnisse allein geeignet gewesen wären, einer großzügigen Einwanderung des deutschen Kapitals als Grundlage zu dienen. Es wurde uns also klar, daß unsere Verhandlungen nicht auf die vertragliche Niederlegung wirtschaftlicher Einzelbestimmungen und Sondervergünstigungen hinauslaufen könnten, sondern mehr allgemeinen Zielen zustreben mußten. Einerseits sollte durch einen Wirtschaftsvertrag öffentlich dokumentiert werden, daß die Beziehungen zwischen Deutschland und Lettland, die seit dem Zusammenbruch unserer Heere gespannte waren und ja bekanntlich im Jahre $1920 \mathrm{zu}$ einer Kriegserklärung geführt hatten, freundschaftlichere geworden seien; alsdann sollte die lettländische Regierung öffentlich dem Wunsch Ausdruck verleihen, daß das deutsche Kapital in stärkerem $\mathrm{Maße}$, als bisher geschehen, sich in Lettland betätigen möge und daß sie bereit sei, hierzu im Rahmen der gegebenen Landesgesetze jede Unterstützung zu gewähren. Schließlich aber sollte, da ja bei der politischen Machtlosigkeit des Reiches dem deutschen Bürger ein wirksamer staatlicher Schutz im Ausland fehlt, der Vertrag unserem diplomatischen Vertreter die 
Handhabe bieten, in konkreten Fällen, in denen dem Deutschen in Lettland unrecht geschähe, auf Grund dieses Vertrages Remedur zu beanspruchen. Diese Wünsche waren diktiert von einem größeren sie beherrschenden Gesichtspunkt, nämlich dem, dem deutschen Element in Lettland festeren Grund unter den Füßen zu verschaffen, ihm die Mögliohkeit zu geben, sich in stärkerem Maße als, bisher geschehen, daselbst anzusiedeln, aus der Überzeugung heraus, daß Lettland einer der natürlichen Hauptwege nach Rußland sei und daß ein wirtschaftlich starkes deutsches Element in Lettland die Rolle des Überleiters des russischen Geschäfts nach Deutschland zu spielen berufen sein werde.

Der Rigaer Vertragsentwurf hat im allgemeinen diesen von Anfang an klar erkannten Zielen entsprochen, und er fand als solcher die fast ausnahmslose Billigung der deutschen Wirtschaftskreise, soweit diese am Handel mit dem Osten interessiert sind. Leider ist der Vertrag nicht von den Regierungen zur Ratifizierung vor die Parlamente gebracht worden, und dies hat seinen Grund darin, daß der schwierige Differenzpunkt zwischen Deutschland und Lettland, nämlich die Entschädigungsfrage, bisher noch nicht aus dem Wege geräumt ist. Die Verhandlungen hierüber haben, trotzdem sie durch den bereits im Juli 1920 geschlossenen Vertrag vorgesehen waren, erst Anfang des Jahres 1922 begonnen. Ich will hier davon absehen, auf Einzelheiten einzugehen. Desto mehr aber liegt mir daran, bei beiden Parteien die Überzeugung zu kräftigen, daß eine Einigung endlich erzielt, die gegenwärtige Dissonanz beseitigt werden muß, daß die Fortdauer der zweifellos vorhandenen und aus der Entschädigungsfrage sich herleitenden Spannung möglicherweise zu einer Verschärfung der beiderseitigen Beziehungen führen könnte, was für die Lösung der östlichen Frage, an der beide Teile in gleichem Maße interessiert sind, schwerwiegende Folgen haben würde.

Es ist klar, daß, um eine beide Teile befriedigende Einigung zu erzielen, mancherlei Hindernisse überwunden werden müssen. Insbesondere bietet die Frage der Entschädigung ( $\$ 5$ des erwähnten Vertrages) recht erhebliche Schwierigkeiten. Andererseits wird die Realisierung des Warenkredits nicht schwer zu erreichen sein, nachdem ausschlaggebende industrielle Kreise grundsätzlich ihre Mitarbeit in dieser Frage zugesagt haben. Es handelt sich also zunächst darum, sich über den Weg klar zu werden, den man beschreiten muß, um zu einer Lösung zu gelangen. Auf diesen Weg habe ich während meiner amtlichen Tätigkeit mehrfach gewiesen und auch bei den beteiligten Stellen Verständnis dafür gefunden. 
Mein Vorschlag ging dahin, eine Verbindung zwischen der Entschädigungsfrage und der Gewährung des Warenkredits herzustellen. Verschmilzt man nämlich diese beiden Fragenkomplexe in einen, schafft man also eine Wechselbeziehung zwischen ihnen, so stützt man die eine Sache durch die andere, vermindert die Hindernisse hier durch die Stoßkraft von dort. Dieser Gedankengang ist so einfach, daß er jedem praktisch Denkenden ohne weiteres einleuchten wird; vorstehende kurze Umrisse meines Vorschlags dürften daher an dieser Stelle genügen. Ich hoffe nicht nur, daß die einflußreichen deutschen Wirtschaftskreise, die mir während meiner amtlichen Tätigkeit ihre Mitarbeit und ihre Unterstützung in dieser Frage haben zuteil werden lassen, sich auch weiterhin bereit finden werden, an der Lösung des Problems tatkrättig mitzuwirken, sondern $\mathrm{da} \mathrm{B}$ auch weitere Kreise in beiden Ländern hieran ein ernstes Interesse nehmen und sich dafür einsetzen werden, daß endlich die Spannung beseitigt wird, die augenblicklich in unseren Beziehungen $\mathrm{zu}$ Lettland besteht.

Fassen wir unsero Betrachtung zusammen, so ersehen wir, daß die außen- und innenpolitische Lage Lettlands den Stempel der Stetigkeit trägt. Im Lande herrscht Ruhe, auch sind die innerpolitischen Gegensätze nicht so extrem wie gegenwärtig in Zentral- und Westeuropa, da die überwiegende Mehrheit des Volkes sich auf einige große Formeln, wie die Agrarreform, geeinigt hat. Außenpolitisch liegt für absehbare Zeit kein Anlaß vor, eine gewaltsame Änderung des gegenwärtigen Zustandes zu erwarten. Mit keinem fremden Staat bestehen Differenzpunkte, die zu militärischen Verwicklungen führen könnten.

\section{Die wirtschaftlichen Verhältnisse Lettlands.}

Es bleibt nunmehr übrig, auf die wirtschaftliche Lage der Republik einen Blick zu werfen. Als die lettländischen Provinzen sich im Jahre 1919 zu einem selbständigen Staat zusammenschlossen, waren die Grundlagen der Volkswirtschaft völlig erschüttert. Der Krieg hatte außerordentlichen Schaden angerichtet. 62000 Letten waren gefallen oder gefangen. Von dem gesamten Gebäudebestand war über $10 \%$, von landwirtschaftlichen Gebäuden über $25 \%$ zerstört. Von ungefähr 5 Millionen ha Landes, die vor dem Kriege unter Kultur waren, lagen 1300000 ha unbebaut, ein Drittel davon ist derart verwüstet, daß eine Neukultivierung unrentabel wäre. Die Eisenbahnstrecken waren in ganzen Abschnitten zerstört, das rollende 
Material in betriebsunfähigem Zustand, Lokomotiven nicht vor' handen. Die bedeutende Industrie in Riga und Libau, von der ein Viertel der Nation existenzabhängig gewesen war, war bis auf die Gebäude vernichtet, die wirtschaftliche Basis Lettlands, nämlich das russische Absatzgebiet und der Transithandel nach Rußland, hatte aufgehört zu bestehen. Unter der neuen Regierung hatte die Zahl der Beamtenschaft überhand genommen, wie das nach Staatsumwälzungen überall $\mathrm{zu}$ geschehen pflegt, ja notwendig ist. Weder war eigenes Geld noch auswärtiger Kredit vorhanden. In dieser Zeit und unter solchen Verhältnissen begannen die schon erwähnten Bemühungen einer englischen Finanzgruppe, aus Lettland einen Koloniestaat zu machen; die bedeutenden natürlichen Reichtümer des Landes mit englischem Geld zu erschließen und auszunutzen, eine landeingesessene Industrie zu schaffen, die Verkehrswege wieder herzustellen, aber wie gesagt, das Land in eine wirtschaftliche Provinz zu verwandeln, waren die Ziele der Tilden-Smith-Gruppe. Die Verhandlungen zogen sich bis über das Jahr 1920 hin und wurden kurz vor ihrem Abschluß durch die nationale Strömung zum Scheitern gebracht, die während der letzten Regierungszeit des Ministerpräsidenten Ullmann einsetzte. Zwischen 1919 und dem Beginn des Jahres 1921 hatte sich zwar die Wirtschaftslage etwas gebessert, immerhin aber konnte doch, nachdem man das ausländische Kreditanerbieten abgelehnt und angesichts aller sich türmenden Schwierigkeiten die Freiheit gewählt hatte, nur eines noch Lettland vor dem wirtschaftlichen Chaos retten, das jetzt, so glaubte man allgemein in Europa, kommen und dem Bestande der jungen Republik ein Ende machen würde, und dies war ein wirtschaftlicher Diktator. Glücklicherweise für Lettland war der Mann dazu da, und anfangs 1921 trat der neue Finanz- und Handelsminister, Ringold Kalning, mit den weitesten Befugnissen ausgestattet, sein Amt an. Kalning, der sich unter dem zaristischen Regime politisch nicht betätigt, dagegen während des Krieges sich durch seine industriellen Unternehmungen zu einem der reichsten Männer Lettlands gemacht hatte, besaß den Vorzug weitgehender internationaler Verbindungen, persönlicher Unabhängigkeit und der Tatsache, daß er sich innerlich seiner Aufgabe gewachsen fühlte. Zunächst stellte er den Grundsatz rigorosester Sparsamkeit auf. Er verringerte den Beamtenapparat, indem er nicht nur 25\% der Budgetforderungen der Ministerien strich und es den Inhabern der Portefeuilles überließ, wie sie danach ihre Ressorts einrichten könnten, sondern auch zwei Ministerien und eine Reihe untergeordneter Organe kurzerhand auf- 
löste. Er verlangte öffentlich rücksichtslos bei jeder Gelegenheit, daß länger gearbeitet und einfacher gelebt werde. Seine Haupttätigkeit konzentrierte sich aber auf die Finanzreform.

Seit der Okkupation war im Baltikum der deutsche Oberostrubel im Umlauf. Die neuen Randstaaten-Republiken standen also vor der wichtigen Frage, ob sie sich mit diesem durch Deutschland gestützten Zahlungsmittel begnügen oder eine eigene Währung einführen wollten. Lettland hatte sich zu letzterem entschlossen. Maßgebend waren hierfür nicht wirtschaftliche Momente, denn bei seiner damaligen desolaten Lage war eine Grundlage für eine eigene Währung, sei es Golddeckung oder ausländischer Kredit, nicht vorhanden; bestimmend war vielmehr die politische Erwägung, daß ein selbständiger Staat keine fremde Münze als Zirkulationsmittel anerkennen könne, daß vielmehr eine eigene Währung sowohl das nationale Empfinden im Innern als die Geltung nach außen hin stärken würde. Tatsächlich wurde dadurch erreicht, daß Lettland vom Völkerbund als selbständiger Staat frühzeitig anerkannt wurde.

Dem Lettenrubel ging es indessen zunächst sehr schlecht. Er wurde durch Gesetz vom 28. März 1920 in ein Zwangsverhältnis zur Reichsmark gebracht und sein Wert auf 2 Mark festgesetzt. $\mathrm{Da}$ Golddeckung nicht vorhanden war, lehnten aber die meisten ausländischen Börsen es ab, ihn $\mathrm{zu}$ handeln und an den wenigen deutschen Börsen, an denen ausschließlich er eingeführt werden konnte, sank sein Wert vom ersten Tage an und erreichte im Juni des Jahres 1921 den Kurs von 13 Pfennigen. Der fast ungedeckte Notenumlauf stieg bis über 2 Milliarden. Es war also noch im vorigen Jahr während unserer Anwesenheit in Riga gar nicht abzusehen, wie je eine Stabilisierung erreicht werden könnte. Die in solchen Fällen übliche Erscheinung trat auch hier auf, der Lettenrubel wurde das Objekt einer wüsten Spekulation und der „schwarzen Börsen"; man konnte ihn häufig 20 \% unter den offiziellen Rigaer Börsennotierungen erwerben. Die Finanzreform, die Kalning nun durchführte, verlief nach folgenden Linien. Es wurde eine neue, zunächst fiktive Münzeinheit, der Goldlat, geschaffen, der einem Goldfrank entsprach. In der Theorie war der Lat als ein fester Münzfuß gedacht, in der Praxis aber blieb zunächst sein Wert ein schwankender, da er ohne Deckung war. Die lettische Regierung ging dazu über, Steuern, Zölle und sonstige öffentliche Abgaben in Goldlat zu erheben, wobei dieser in das feste Wertverhältnis von $1 \mathrm{zu} 100 \mathrm{zum}$ Papierrubel gebracht wurde. Dies war lediglich die Vorbereitung für die Einführung einer Gold- 
währung, die Kalning durchzusetzen hoffte. Das Mittel hierfür sollte eine Emissionsbank sein, an der sich das Ausland mit zwei Drittel des Kapitals beteiligen sollte.

Um einer fortschreitenden Entwertung des lettischen Papierrubels vorzubeugen, hatte Kalning sogleich nach seinem Amtsantritt die Emission weiterer Scheine inhibiert. Dieses bewirkte natürlich in kurzer Zeit eine außerordentliche Geldknappheit im Lande und eine vollkommene Stagnation des Handels. Da inzwischen aber die rücksichtslose Sparsamkeit innerhalb der Regierung durch Verringerung der Zahl der Gehaltsempfänger durchgeführt war, und andererseits die durch die Geldknappheit hervorgerufenen wirtschaftlichen Rückschläge im wesentlichen die fremden Importeure trafen, ließen den Finanzminister diese Folgen seiner Politik ziemlich kalt. Hätte in Lettland noch eine nennenswerte Industrie bestanden, hätte also ein Arbeiterproletariat beschäftigt und entlohnt werden müssen, dann wäre dieses diktatorische Verfahren schwer durchzuführen gewesen und hätte wahrscheinlich in einer Revolution geendigt. So aber waren die wirtschaftlichen ersten Rückschläge dieser Finanzpolitik $\mathrm{zu}$ ertragen und es wurde durch sie sehr bald eine Stabilisierung erreicht, der Lettenrubel fiel nicht nur nicht mehr sondern stieg im Werte, wie aus folgendem Vergleich mit der Mark hervorgeht, zu einer Zeit, als diese noch als ein Wertmesser angesehen werden konnte:

\begin{tabular}{c|c|c}
\hline Datum & $\begin{array}{c}\text { Stand der Mark in } \\
\text { Goldpfennig auf Basis } \\
\text { des Dollarkurses }\end{array}$ & $\begin{array}{l}\text { Man erhielt für } \\
\text { 100 Papiermark } \\
\text { in Lettenrubeln }\end{array}$ \\
\hline am 1. 6. 1921 & 6,6 & $805,-$ \\
am 1. 7. 1921 & 5,6 & $685,-$ \\
am 1. 8. 1921 & 5,18 & $505,-$ \\
am 1. 9. 1921 & 4,9 & $435,-$ \\
am 1. 10. 1921 & 3,3 & $320,-$ \\
am 1. 11. 1921. & 2,3 & $171,-$ (am 3. 11.) \\
am 1. 12. 1921 & 2,2 & $101,-$
\end{tabular}

Es hatte sich also bis zum Ende des Jahres 1921 die Finanzpolitik des Wirtschaftsdiktators bereits erfolgreich im Stand des Lettenrubels zum Ausdruck gebracht. Hinzu kam, daß durch die allmähliche Stabilisierung der inneren und äußeren Verhältnisse es inzwischen gelungen war, neue Einnahmequellen für den Staat zu eröffnen bzw. die bestehenden zu erweitern. Hierzu gehören vor allem die Zolleinnahmen aus importierten Waren, die staatlichen Monopole auf Flachs und Spiritus, endlich auch die Ein- 
nahmen aus den Staatswäldereien. In welchem Ausmaße die Ertragfähigkeit dieser Einnahmequellen unter dem neuen Regime gesteigert wurde, zeigt nachstehende Übersicht über die finanzielle Lage der hauptsächlichen Staatsunternehmen in den Budgetjahren 1920/21 und 1921/22.

$\begin{array}{cc}\text { Tatsächlicher } & \text { Veranschlagt } \\ \text { Bestand } & 1921 / 22 \\ \text { 1920/1921 } & \end{array}$

\section{A. Staatsmonopole.}

1. Flachsmonopol. In Goldfranken.

Brutto-Einnahme............... 16,513 $854 \quad 23220000$

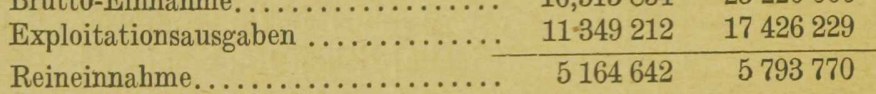

2. Ledermonopol

Brutto-Einnahme............... $318396 \quad 1438056$

Exploitationsausgaben ............... $2506441 \quad 1114308$

Gewinn oder Defizit ............ $-2188045+323748$

3. Spiritus-Monopol.

Brutto-Einnahme............... $8018108 \quad 20865311$

Exploitationsausgaben ............. $3507631 \quad 6106341$

Reineinnahme............... $4510477 \quad 14758970$

B. Staatliche Unternehmen.

1. Eisenbahnen.

Brutto-Einnahme............... $7822384 \quad 17868852$

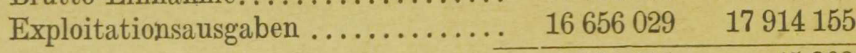

Reines Defizit .............. $8833645 \quad 45303$

2. Post-Telegraph-Telephon.

Brutto-Einnahme............... $2338478 \quad 3686065$

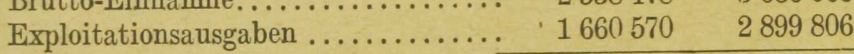

Gewinn ............. +677908+786259

3. Forstwirtschaft.

Brutto-Einnahme.............. $2720730 \quad 5081967$

Exploitationsausgaben ........... $6050067 \quad 1808257$

Gewinn oder Defizit ........... $-3329337+3273710$

4. Versorgungs-Unternehmen.

Brutto-Einnahmen ............. 5021996

Exploitationsausgaben ........... 15 319343 -

Defizit ................... -

5. Torfwirtschaft.

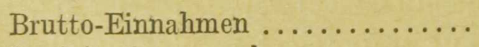

Exploitationsausgaben .............

Reineinnahmen .................

$829958 \quad-$

821047

$8911 \quad 24590$ 


$\begin{array}{cc}\text { Tatsächlicher } & \text { Veranschlagt } \\ \text { Bestand } & 1921 / 22 \\ 1920 / 1921 & \end{array}$

6. Einnahmen von staatlichen Schiffen.

$\begin{array}{lrr}\text { Brutto-Einnahmen ................ } & 2007441 & - \\ \text { Exploitationsausgaben ............ } & 881538 & - \\ \text { Reineinnahme................... } & 125903 & -\end{array}$

7. Staatliche Ländereien $\mathrm{u}$. Wälder.

\begin{tabular}{lrr} 
Brutto-Einnahmen ............... & 3184668 & 20736566 \\
Exploitationsausgaben ............ & 3076909 & 12143448 \\
\hline Reineinnahme.................. & 107759 & 8593118
\end{tabular}

$\mathrm{Ob}$ auch die privaten enteigneten Waldungen herangezogen worden sind, um der Staatskasse Gelder zuzuführen, läßt sich von einem Außenstehenden nicht beurteilen. Die Vermutung liegt aber nicht zu fern, daß Kalning auch in diesem Punkte mit derselben Rücksichtslosigkeit vorgegangen ist wie in anderen. Wahrscheinlich aber hätten die geschilderten Maßnahmen allein auch nicht zum Ziele geführt, wenn nicht Hand in Hand mit den Finanzmaßnahmen eine allgemeine Gesundung der wirtschaftlichen Verhältnisse eingetreten wäre. Insbesondere war es der Handel, der, durch die Stabilisierung des Lettenrubels und durch den aufs neue erwachenden Bedarf Sowjetrußlands angeregt, sich bald wieder erholte und ausbreitete, so daß die Handelsbilanz Lettlands bereits anfangs 1922 aktiv wurde. Auch strömte über gewisse Grenzhandelspunkte, über die ein großer Teil des Warenverkehrs zwischen Lettland und Sowjetrußland geht, der nicht in den offiziellen Statistiken nachgewiesen wird, viel Gold und Goldwerte herein, die die Reserven des Finanzministeriums weiterhin verstärkten.

Nunmehr war die Zeit herangekommen, in der Kalning ernstlich an die Errichtung der Emissionsbank denken konnte. Im Sommer des Jahres 1922 verfügte das Finanzministerium bereits über einen derartigen Bestand an Gold und Devisen, daß der Grundstock für das Emissionsinstitut dadurch gelegt war. Die Hauptlinien des neuen Unternehmens waren wie folgt gezogen:

Die „Latwija Bank" erhält ein Kapital von 75 Millionen Goldfrank, welches zur größeren Sicherheit gänzlich außerhalb Lettlands zu halten, und zwar in London zu deponieren ist; hiervon wird ein Drittel von der lettländischen Regierung und lettländischen Bürgern und zwei Drittel von Angehörigen der drei Großmächte aufgebracht, und zwar in der folgenden Proportion:

$30 \%$ von britischen Finanzleuten,

$30 \%$ in den Vereinigten Staaten von Amerika,

$10 \%$ von französischer Seite. 
Der Verwaltungsrat soll bestehen aus:

zwei Drittel lettländischen Bürgern, ein Drittel Ausländern;

letztere werden zu einer Gruppe vereinigt, die ihren Sitz in Riga hat und die unter gewissen Bedingungen ein Vetorecht besitzt. Die Latwija Bank ist berechtigt, Darlehen an die lettische Regierung oder an Kommunalinstitutionen zu gewähren, Banknoten zu emittieren, deren Deckung in Devisen oder Gold zu bestehen hat. Die lettländische Regierung beansprucht für sich:

1. eine Prämie auf die Anteilscheine, und zwar 10-15\%,

2. einen Teil des Diskonts, und zwar ein Drittel,

3. eine geringe Steuer auf die zirkulierenden Banknoten, und zwar für einen Umlauf von 100 Millionen $1 \%$, von 100 bis 200 Millionen $2 \%$ usw. in progressiver Proportion,

4. das Recht, unter gewissen Umständen die Aktien zurückzukaufen, wobei der Gewinn der ausländischen Aktienbesitzer nicht geschmälert werden solle.

Der Finanzminister war fest davon überzeugt, daß es erforderlich sei, dem Goldlat eine internationale Stütze zu geben, das Ausland an dem Projekt zu beteiligen. Die Teilnahme der drei Ententenationen erschien ihm daher so wichtig, daß er, um noch bestehende Schwierigkeiten zu überkommen, vorschlug, der Völkerbund solle durch sein Finanzdepartement einen Vertrauensmann in den Ausschuß delegieren.

Kalning hat sein Werk nicht zu Ende führen können, da ihm im eigenen Lager Schwierigkeiten erwuchsen. Die radikalen Elemente im lettischen Kabinett stellten sich auf den Standpunkt, daß Lettland heute imstande sei, ohne Zuhilfenahme fremden Kapitals, aus eigener Kraft vielmehr, die Emissionsbank zu schaffen. Der Finanzminister sah sich von seinen Kollegen verlassen und zog die Folge daraus, indem er sein Portefeuille aufgab. Als er sein Amt antrat, waren in der Staatskasse etwa $100000 £$ vorhanden, als er es nach $1 \frac{1}{2}$ jähriger Verwaltung niederlegte, verfügte sie über $1200000 £$ Goldwerte, und er hatte ein Budget für das Jahr 1922/23 vorbereiten können, in dem die Ausgaben mit den Einnahmen balancierten. Auch sonst hat er die Fundamente gelegt, auf denen sich die lettländische Wirtschaft wieder neu aufbauen wird. Die Grundsätze, nach denen er handelte, waren bedenkenlose, diktatorische. Aber eine auf wankenden trümmerhaften Grundlagen ruhende, der Auflösung entgegenrollende Volkswirtschaft kann nicht vor dem Chaos gerettet werden, wenn die leitenden Männer in dem Lärmen der Straße ihren obersten 
Leitstern und in der Wirtschaft ein Handelsobjekt für politische Parteien erblicken. Eine todkranke Wirtschaft kann nur durch einen eisenharten Arzt geheilt werden. Dieses hat in einer kurzen, aber bedeutungsvollen Amtstätigkeit der Finanzminister Kalning den heutigen Regierungen vor Augen geführt.

Die Gesundung der Wirtschaft zeigt sich auch besonders in der Verbesserung der Eisenbahnen. Von den während des Krieges und der Revolution zerstörten 384 Bahngebäuden sind $22 \%$ wieder hergestellt. Der Wagenpark ist seit 1919 um das $21 / 2$ fache gestiegen, die Menge der elektrischen Anlagen um das 4-5fache. Der Verkehr hat sich entsprechend gehoben, die Wagenkilometerzahl hat sich zwischen 1920 und 1921 um $42 \%$ erhöht. Die Steigerung des Schiffsverkehrs um $65 \%$ ist bereits bemerkt worden.

Ich habe eingangs erwähnt, daß man unter den Letten ebensolch intelligente, gebildete und geschäftstüchtige Individuen findet, wie man sie in den westlichen Teilen Europas trifft; ich möchte hinzufügen, daß die Signatur besonders der Rigaer gebildeten Kreise eine gewisse Weltmännischkeit und Sicherheit in dei Beherrschung von Situationen ist, die sich gar nicht mit dem ber uns üblichen Bilde vom Osten vereinbaren läßt, und die wohl auf die hanseatische Vergangenheit der Stadt zurückzuführen ist. Immerhin bezieht sich dieses nur auf die oberen Schichten, die Masse des Volkes muß ihrer ganzen geschilderten Entwicklung nach sein und ist tatsächlich intellektuell tieferstehend als die sorgfältig geschulten, breiten Massen der westlichen Nationen. Das lettische Volk wird daher aus eigener Kraft eine genügend starke Oberschicht, Führer des öffentlichen und wirtschaftlichen Lebens, in genügender Anzahl nicht hervorbringen können, um alle die Plätze zu füllen, die die Bedeutung Rigas schaffen wird, ja, der Mangel an solchen Individuen macht sich heute schon dem unbefangenen Beobachter bemerkbar. Man sehe hierin keinen Widerspruch zu meinen früheren Ausführungen. Die heute in Lettland lenkenden und leitenden Männer sind zwar Nationalletten, haben aber ihre politische und wirtschaftliche Ausbildung meist in Rußland genossen, ihnen stand also als Schulund Lehrboden der weite russische Staats- und Wirtschaftskörper zur Verfügung. In Zukunft dagegen muß der Nachwuchs auf dem engen Umkreis des lettischen Landes aufgezogen werden. In seinem gegenwärtigen Zustand nun hat das Land weder die kulturelle Stufe noch den ökonomischen Entwicklungsgrad erreicht, um 
der Nährboden sein zu können, auf dem sich aus dem Volke heraus großzügige, weitblickende und abgerundet gebildete Führer der Wirtschaft entwickeln, Leute, die den modernen westeuropäischen Phöniziern gewachsen wären.

Daher möchte man wünschen, daß dem deutsch-baltischen Element, das durch den Krieg entwurzelt worden ist und seine Bodenständigkeit verloren hat, bald wieder die Möglichkeit gegeben werde, sich im Rahmen und Gefüge des neuen Staates öffentlich und wirtschaftlich zu betätigen. Man hat vielleicht in Lettland

- noch nicht voll erkannt, wie notwendig für einen Staat, um zu florieren, eine geschäftlich erfahrungstüchtige und großzügige Oberschicht ist, daß Rohstoffe und alle Begünstigungen, welche die Natur einem Lande verliehen haben mag, nichts nützen, wenn nicht Menschen da sind, die es verstehen, sie auszuwerten, und daß man sich durch die Ausschaltung des deutsch-baltischen Elementes einer Bevölkerungsschicht beraubt hat, die gerade bei der weiteren Konsolidierung der Wirtschaft dem Lande große Dienste leisten könnte. Es ist von entscheidender Bedeutung für Lettland, einen Ausgleich mit dieser Klasse zu finden und sie zur tätigen Mitarbeit wieder heranzuziehen.

\section{Unsere Betätigungsmöglichkeiten in Handel und Industrie.}

Das Bild, das in dem engen Rahmen dieser Arbeit von Lettland gegeben werden konnte, ist vollendet. Ich möchte nunmehr noch eine Frage erörtern, die Handel und Industrie bei uns vor allem interessieren $\mathrm{muß}$ und die lauten wird: Sollen die deutschen Wirtschaftskreise sich bereits jetzt in Lettland aktiv betätigen?

Als Ausgangspunkt möge das Ergebnis unserer bisherigen Betrachtungen nochmals zusammengefaßt werden: Wir haben die Überzeugung gewonnen, daß Lettland mit der Hauptstadt Riga seine Bedeutung als Transitland für das europäische Rußland nicht verlieren wird, da diese Bedeutung auf natürlichen Grundlagen beruhte, die sich durchsetzen werden, auch wenn vorübergehend aus politischen Erwägungen versucht wird, sich über sie hinwegzusetzen. Wir haben ferner gesehen, daß die Agrarproduktion der Republik nicht erschüttert worden ist, daß Lettland vielmehr als Lieferant wichtiger Rohstoffe auch in Zukunft in Betracht kommt und hierin auch für Deutschland eine nicht unerhebliche Bedeutung besitzen wird. Wir haben des weiteren festgestellt, daß in den außenpolitischen Verhältnissen es keine Faktoren gibt, die uns zwingen, 
mit einer Veränderung des gegenwärtigen Zustandes in absehbarer Zeit zu rechnen. Die innerpolitischen Verhältnisse sind stabil, und eine bolschewistische Gefahr ist nicht zu befürchten. Andererseits haben wir festgestellt, daß obgleich die lettländische Industrie auf natürlichen Grundlagen beruhte, dennoch die Hauptvoraussetzung ihrer Existenz, nämlich die Absatzmöglichkeit auf dem russischen Markt, vorläufig mehr als unsicher ist, daß daher gegenwärtig die eigentliche Grundlage fehlt, auf der eine neu zu errichtende Industrie sich aufbauen müßte. Ferner entbehren die Beziehungen zwischen Deutschland und Lettland einer gewissen Klarheit; ein wichtiger Streitpunkt muß aus dem Wege geräumt werden; auch besteht noch kein Handelsvertrag, der die gegenseitigen Wirtschaftsbeziehungen auf eine staatsrechtliche Grundlage bringt, dem Deutschen in Lettland gesicherte Rechte gibt und ihm Schutz und Gewähr in der Ausübung seiner Tätigkeit verbürgt. Das Fehlen dieses Vertrages aber verstärkt die allgemeine Zurückhaltung, die man seit der russischen Revolution bei uns und in ganz Europa dem Osten entgegenbringt. Endlich hat die in Lettland herrschende nationalistische Strömung den Grundsatz aufgestellt: ,Lettland für die Lettländer", und unter dieser Devise versucht man, alle wirtschaftlichen Vorteile möglichst dem Lettländer auf Kosten des Ausländers zukommen zu lassen. Auch wird die Anknüpfung neuer Beziehungen und die Aussicht auf einen Nachwuchs, der den großen Zukunftsaufgaben Rigas adäquat wäre, dadurch erschwert und vermindert, daß das deutsch-baltische Kaufmannselement, das seit Jahrhunderten der Hauptträger der kulturellen Beziehungen zwischen Deutschland und dem heutigen Lettland war, daselbst entwurzelt und aus seinem öffentlichen und privaten Wirkungskreis verdrängt worden ist.

Der Entschluß, sich vorläufig vom lettländischen Markt zurückzuhalten, wäre also sowohl aus Einzelerwägungen wie aus unserer gesamten psychologischen Einstellung dem Osten gegenüber verständlich. Aber hiermit ist die Frage nicht ausgeschöpft.

Es ist eingangs erschöpfend dargelegt und als die wichtigste Beziehung, unter der wir Lettland zu betrachten haben, hingestellt worden, daß dieses Land das wirtschaftliche Vorgelände und Haupteinfalltor nach dem Osten darstellt. Es ist sehr wahrscheinlich, daß der größere Teil der Geschäfte mit Großrußland in den nächsten Jahren in Riga vorbereitet oder abgeschlossen werden, und zwar besonders dann, wenn nach der Freigabe der Privatwirtschaft in Rußland, mit der man bereits begonnen hat, der Einzelne wieder als Käufer und Importeur im Auslande auftreten kann. 
Es wird dann zum Beispiel bei uns noch immer für sicherer gelten, Konsignationsläger nach Riga zu legen als nach Sowjetrußland, bei dem eine vollständige Klärung seiner inneren Verhältnisse und davon abhängig ein höherer Sicherheitsgrad für geschäftliche Unternehmungen erst zu einer fernerliegenden Zeit erwartet werden kann.

Wenn das deutsche Element in wirtschaftlichen Dingen einen großen Machtfaktor im zaristischen Rußland darstellte, so gilt dies besonders vom Baltikum. Ich denke hierbei nicht nur an die Deutsch-Balten, sondern auch an die deutschen Staatsangehörigen, die sich in den baltischen Provinzen niedergelassen, ihre Staatszugehörigkeit aber nicht geändert hatten. Diese waren die eigentlichen Vermittler des Warenaustausches zwischen Rußland und Deutschland. Sie leisteten die Pionierarbeit für unsere Industrie, sie waren ihre besten Agenten und Verkäufer. Daher ist es nur folgerichtig, daß wir jetzt bestrebt sein müssen, es den Deutschen wieder zu ermöglichen, sich in Lettland niederzulassen, dort festen Fuß zu fassen, um dann über Riga, über Lettland, den Vermittler zwischen Rußland und dem Westen zu spielen. Halten sich nun aber, um auf die eben geführte Überlegung zurückzukommen, die großen deutschen Häuser vom Geschäft mit Lettland zurück, so werden ohne Zweifel an ihrer Stelle sich andere Ausländer, unsere Konkurrenten, dort niederlassen. Von vielen Seiten wird zwar behauptet, daß gleichgültig, welche Mitbewerber auch immer im Osten auftreten, das Geschäft dennoch uns zufallen muß und wird, da wir allein völlig mit den Bedürfnissen des Ostens vertraut und allein imstande seien, diese Bedürfnisse zu befriedigen. Gewiß liegt hierin etwas Wahres, es wäre aber ein trauriger Fehler, wollte man hiervon ausgehend die Hände in den Schoß legen. Schon vor dem Kriege war unsere Stellung im russischen Ein- und Ausfuhrhandel, besonders in der Rigenser Einfuhr, durchaus nicht so unbestritten, wie dieses im allgemeinen geglaubt wird. Als Beweis hierfür diene Tabelle 5 (S. 63). Danach stand im Jahre 1913 an erster Stelle England mit ungefähr 43,2 \% der gesamten Einfuhr, Deutschland an zweiter Stelle mit $36,6 \%$.

Seit dem Kriege nun hat der Handelsverkehr andere Bahnen genommen und sich mehr zugunsten Deutschlands entwickelt. Ich lasse hierfür zwei Tabellen folgen, von denen die erste den Außenhandel Lettlands im Jahre 1920, die zweite den des Jahres - 1921 wiedergibt. (Tabelle 6 u. 7, S. 63, 64.)

Obgleich infolge des Erliegens der Rigaer Industrie der Haupteinfuhrartikel aus England, die Kohle, gänzlich weggefallen war, stand GroBbritannien im Jahre 1920 noch immer mit $21 \%$ des 
Gesamtbetrages an zweiter Stelle der einführenden Länder, an der Spitze stand Dänemark mit $22 \%$, als dritter erst kam Deutschland mit $19 \%$. Was die Ausfulur anlangt, so gingen von den lettischen Erzeugnissen 67 \% nach Großbritannien, es folgten Holland mit $10 \%$, dann Belgien, Frankreich, Dänemark, Schweden; nach Deutschland gingen nennenswerte Mengen überhaupt nicht, im ganzen nur 11/2\%. Dieses ungünstige Bild hat sich im Jahre 1921 gänzlich verändert; Deutschland ist als Lieferant an die erste Stelle getreten, als Kunde an die zweite Stelle. Es wäre aber nichts mehr irrtümlich, als etwa aus dieser günstigen Entwicklung zu schließen, daß wir nunmehr den Rigaer Markt beherrschen, uns dieses schwierige Terrain für die Zukunft gesichert haben. Der Fall der Mark, diese große Prämie für die deutsche Ausfuhr, hat sich in unserem Handel nach dem nahen Osten noch stärker ausgewirkt als nach westlichen und überseeischen Ländern. Die Verbesserung der ökonomischen Verhältnisse in Lettland hat ferner bewirkt, daß man die Waren, die die Republik in ihren ersten Notjahren aus England und Dänemark bezog, jetzt nicht mehr in gleichem Maße einführt, während die Erzeugnisse, die man vor dem Kriege vorzugsweise aus England kaufte, Kohlen und Industriemaschinen, noch gar nicht oder wenigstens noch nicht in dem gleichen Ausmaß benötigt werden, wie das der Fall sein wird, sobald Sowjetrußland wieder als Absatzmarkt in Betracht kommt. Es kommt hinzu, daß das Ausland die Bedeutung der Randstaaten als wirtschaftliches Vorgelände für Rußland vom ersten Tage an erkannt hat. Ganz besonders war dies bei England der Fall. Nur mit englischer Hilfe hat Lettland sich überhaupt vom russischen Staatskörper lostrennen, sich zu einem selbständigen Staat machen können, und bereits im Jahre 1919 erklärte Mr. Asquith im englischen Parlament, daß von jetzt ab die russischen Randstaaten zur Interessensphäre des Britischen Reichs zu rechnen seien. Es haben denn auch englische Handelsunternehmungen ohne Zeitverlust versucht, die Rohstoffquellen des Landes mit Beschlag zu belegen. Das erste Staatsmonopol, das in Lettland gegründet wurde, für Flachs, wurde einer englischen Finanzgruppe zur Ausbeutung übertragen. Die einzige größere Waldkonzession, die die Regierung vergeben hat, ist einem englischen Konsortium zugefallen. Aber auch Schweden und Dänemark haben Geld in lettische Unternehmungen gesteckt, und man trifft dort Staatsangehörige aller Länder dem Geschäft nachgehend. Demgegenüber ist die Beachtung, die Lettland in den weiteren Kreisen des Handels bisher bei uns gefunden hat, gering. Wieviel große deutsche Firmen haben dort Niederlassungen? Ja, wieviel kennen überhaupt die 
Bedeutung Lettlands für Gegenwart und Zukunft? Zögern wir aber noch lange, so wird uns der Grund und Boden entrissen werden, auf dem wir festen Fuß fassen müssen, wollen wir nicht unsere zukünftigen Interessen im Osten gefährden.

Man kann nun nicht mit der uneingeschränkten Forderung vortreten, daß der deutsche Kaufmann sich rückhaltlos dem lettischen Markt zuwenden, dorthin schrankenlos Geschäfte machen müsse. Eine solche allgemeine Forderung kann überhaupt nicht gestellt werden. Für jeden Geschäftszweig und jede Warenart sind die gegebenen Marktverhältnisse andersartig. Ein jeder Kaufmann wird daher vom Standpunkt seines eigenen Unternehmens erwägen müssen, ob er überhaupt sich in Lettland betätigen wolle und könne und ob ihm der Moment dazu geeignet erscheine. Aber für dieses Eine muß der deutsche Wirtschaftspolitiker in der Öffentlichkeit mit stärkstem Nachdruck eintreten, daß nämlich die führenden Unternehmungen Deutschlands, die, welche wir gewohnt sind, als die Pioniere unseres Wirtschaftslebens zu betrachten, ihr Interesse mehr als dies bisher geschehen dem lettischen Markt zuwenden, daß sie ihn an Ort und Stelle studieren und auch hier und dort zu einem gewagten Geschäft bereit sein mögen, wenn sie überhaupt in der Zukunft sich Gewinn vom Osten versprechen. Das wenigste, was große am Handel mit dem Osten interessierte deutsche Geschäftsunternehmungen heute als ihre Pflicht ansehen müßten, wäre, Beobachtungsposten nach Lettland zu setzen, die Verbindungen anknüpfen, vor allem aber das Stammbaus über alle Entwicklungen des Marktes und der allgemeinen wirtschaftlichen Situation auf dem Laufenden halten. Hierbei dürfte es nicht genügen, daß man seine Vertretung einem der zahlreichen in Lettland ansässigen Agenten anvertraut, sondern bei der Wichtigkeit des Terrains ist es geboten, seine Interessen von einem festangestellten Beamten wahrnehmen zu lassen, der aus dem eigenen Betrieb hervorgegangen, sowohl die Intentionen seines Stammhauses kennt, als auch jede Phase der Entwicklung daraufhin beurteilen kann, ob und in welcher Weise sie für sein Haus wichtig, vorteilhaft oder nachteilig ist.

Es ist bisher vom Handelsgeschäft gesprochen worden, in dem man sein Kapital wohl wagt, aber verhältnismäßig leicht und schnell umschlägt und flüssig erhält. Viel schwieriger wird das Problem, wenn es sich um die Entscheidung handelt, ob sich Deutschland auch an der Wiederaufrichtung der lettischen Industrie mit Kapital und Arbeitskraft beteiligen solle. Könnte man sich hierbei darauf beschränken, auf meine früheren Darlegungen 
der industriellen Lage Lettlands zurückzugreifen, so würde die Entscheidung nicht schwierig sein. Man würde die gestellte Frage dann negativ beantworten, aus der Erwägung heraus, daß die industrielle Zukunft noch ungeklärt, die Entwicklungsmöglichkeiten für die neu zu errichtende Industrie noch nicht zu überschauen seien; anstatt jetzt schon sein Kapital zu binden, würde man also die weitere Entwicklung abwarten und sich vorläufig näherliegenden Aufgaben zuwenden. Unglücklicherweise is t aber die Frage mit diesen Argumenten nicht abgetan, jedenfalls nicht vom nationalen Standpunkt, der letzten Endes auch immer der beste privatwirtschaftliche ist.

Es wird jedem offensichtlich werden, der nach Lettland fährt und die Verhältnisse an Ort und Stelle kennenlernt, daß dasjenige fremdländische Element sich dort am festesten niederlassen, die tiefsten und stärksten Wurzeln schlagen wird, das der Träger der neuen Industrie wird. Wer die Industrie in seiner Hand hat, wird nicht nur notwendigerweise innerpolitischen Einfluß besitzen; wird nicht nur die stärksten Brücken nach Rußland schlagen, sondern er wird auch seinen Einfluß im Rigaer Großhandel und damit im Transithandel geltend machen. Daß letzteres keine bloße Vermutung ist, beweist die Vorkriegsstatistik, wonach $50 \%$ aller im Frieden nach Riga eingeführten Waren für die dortige Industrie bestimmt waren. Diese wirtschaftlichen Zusammenhänge haben auch die mit uns konkurrierenden Nationalitäten bereits erkannt. Engländer, Franzosen, Schweden, Belgier interessieren sich seit langem für die Wiederaufrichtung der lettischen Industrie, studieren die Verhältnisse an Ort und Stelle und führen Unterhandlungen über den Erwerb von Eigentum und die Errichtung von Fabriken. Die Bereitschaft Englands, große Kapitalien zur Wiederaufrichtung der lettischen Industrie zu verwenden, haben die früher erwähnten Verhandlungen der Tilden-Smith-Gruppe gezeigt. Die Böckersche Werft, das bedeutendste industrielle Unternehmen in Libau, hat als englische Gesellschaft ihren Betrieb eröffnet. Gegenwärtig wird darüber verhandelt, daß eine der früheren industriellen Großunternehmungen in Riga in ausländische, nichtdeutsche Hände übergehen und den Betrieb wieder aufnehmen solle. Konservenfabriken sind in großem Maße mit fremdländischem, hauptsächlich mit schwedischem Kapital eröffnet worden.

Gegenüber dieser ausländischen Betriebsamkeit müssen wir also vom nationalen Standpunkte wünschen, daß Deutschland nicht zu spät komme, und die Gefahr, die hierin für uns liegen würde, soll an einem konkreten Beispiel demonstriert werden. 
Die Gebäude der früheren Fabriken in Riga, die, ihrer maschinellen Einrichtungen beraubt und auch vielfach beschädigt, heute leer und verlassen dastehen, bilden immerhin einen wertvollen Besitz. Ein als Industrieorganisator bekannter Fachmann, der eine Reihe dieser Gebäude besichtigt und sie auf ihre industrielle Verwertbarkeit geprüft hat, hat mir versichert, daß die Mehrzahl von ihnen vorzüglich gebaut seien und den Erfordernissen moderner industrieller Technik entsprächen; man könne die meisten von ihnen mit verhältnismäßig geringen Aufwendungen für Instandsetzung wieder für ihren ursprünglichen Zweck verwendbar machen. Diese Immobilwerte nun sind gegenwärtig zu verhältnismäßig geringen Preisen zu erwerben, und die Gefahr besteht, daß das Ausland uns hierbei zuvorkommt. Wer aber heute sein Fabrikgebäude billig erworben hat, wird später in der Lage sein, mit geringeren Unkosten zu fabrizieren, daher leistungsfähiger sein als derjenige, der einen Neubau unter Aufwendung der hohen und wahrscheinlich in absehbarer Zeit nicht sinkenden Baukosten aufführen muß. Zwar können Ausländer Grundbesitz in Lettland nur mit Genehmigung der Regierung erwerben, diese Bestimmung bietet aber keine tatsächlichen Schwierigkeiten.

Wenn ich, indem ich meine Ausführungen rückschauend zusammenfasse, auch hier nicht mit verhängten Zügeln reiten kann, wenn auch hier nicht die Forderung aufgestellt werden soll, daß nun deutsches Kapital rückhaltlos für die Wiederaufrichtung der lettischen Industrie zur Verfügung gestellt werden müsse, so werden andererseits die gleichen Postulate nicht unbillig erscheinen, wie sie für das Handelsgeschäft aufgestellt worden sind. Eifriges Studium der industriellen Frage an Ort und Stelle, Eingehen auf alle Einzelheiten, Untersuchung, ob und welche der früheren industriellen Unternehmungen wieder ins Leben gerufen werden können, das sind die zunächst liegenden Aufgaben, die an uns gestellt werden.

In dem großen Stil westeuropäischer Werke wird man natürlich ein industrielles Unternehmen in Lettland für absehbare Zeit noch nicht ins Leben rufen dürfen. Jede Betätigung dort, sei sie im Handel oder Industrie, wird vorerst sich darauf beschränken, entsagungsreiche Kleinarbeit zu sein. 


\section{Berichtigungen.}

Seite 15 Zeile 10 des Textes v. u. lies statt Mitan: "Windau“.

" 20 Zeile 10 v. 0 . lies statt Kjäsan: „Rjasan“.

" 20 Zeile 19 v. o. lies statt Orenberg: "Orenburg".

" 20 Zeile 25 v. o. lies statt Kostrona: "Kostroma“.

" 21 Zeile 4 v. o. lies statt Nowarascisk: Noworosslisk".

" 25 Zeile 22 v. o. lies statt Dahlem: "Dahlen“.

" 25 vorletzte Zeile lies statt Dahlem: "Dahlen“.

" 27 Zeile 9 v. u. lies statt Inventur: "Inventar".

" 32 Zeile $3 / 4$ streiche einmal „vor".

" 56 Zeile 9 v. u. lies statt $36,6 \%$ : „33,6\%".

" 57 Zeile 2 v. o. lies statt $22 \%$ : ,24\%". 
Wert des Gesamtumsatzes der Ostseehäfen und Odessas im auswärtigen Handel Rußlands.

Tabelle 1.

(Export und Import zusammen.)

\begin{tabular}{|c|c|c|c|c|c|c|c|c|c|c|c|c|c|c|}
\hline \multirow[b]{2}{*}{ a f e $n$} & $\begin{array}{l}1891-1895 \\
\left(\text { durchschn }_{i}\right)\end{array}$ & \multirow{2}{*}{$\begin{array}{c}\% \text { v. Wert } \\
\text { des russ. } \\
\text { Gesamt- } \\
\text { umsatzes }\end{array}$} & $\begin{array}{r}1896-1900 \\
\text { (durchschn.) }\end{array}$ & \multirow{2}{*}{$\begin{array}{c}\% \text { v. Wert } \\
\text { des russ. } \\
\text { Gesamt- } \\
\text { umsatzes }\end{array}$} & $\begin{array}{c}1901-1905 \\
\text { (durchschn.) }\end{array}$ & \multirow{2}{*}{$\mid \begin{array}{c}\% \text { v. Wert } \\
\text { des russ. } \\
\text { Gesamt- } \\
\text { umsatzes }\end{array}$} & $\begin{array}{r}1906-1910 \\
\text { (durchschn.) }\end{array}$ & \multirow{2}{*}{$\left|\begin{array}{c}\% \text { v. Wert } \\
\text { des russ. } \\
\text { Gesamt- } \\
\text { umsatzes }\end{array}\right|$} & 1911 & \multirow{2}{*}{$\left|\begin{array}{c}\% \text { v. Wert } \\
\text { des russ. } \\
\text { Gesamt- } \\
\text { umsatzes }\end{array}\right|$} & 1912 & \multirow{2}{*}{$\begin{array}{c}\% \text { v. Wert } \\
\text { des russ. } \\
\text { Gesamt- } \\
\text { umsatzes }\end{array}$} & 1913 & \multirow{2}{*}{$\begin{array}{l}\% \text { v. Wert } \\
\text { des russ. } \\
\text { Gesamt- } \\
\text { umsatzes }\end{array}$} \\
\hline & $\begin{array}{l}\text { Wert in } \\
\text { Rubeln }\end{array}$ & & $\begin{array}{l}\text { Wert in } \\
\text { Rubeln }\end{array}$ & & $\begin{array}{l}\text { Wert in } \\
\text { Rubeln }\end{array}$ & & $\begin{array}{l}\text { Wert in } \\
\text { Rubeln }\end{array}$ & & $\begin{array}{l}\text { Wert in } \\
\text { Rubeln }\end{array}$ & & $\begin{array}{l}\text { Wert in } \\
\text { Rubeln }\end{array}$ & & $\begin{array}{l}\text { Wert in } \\
\text { Rubeln }\end{array}$ & \\
\hline ga & 28 & 8, & 18 & 11,1 & 1 s & & 27 & 15,9 & 334106 & 14,9 & & 16,6 & & 17 \\
\hline Petersburg & 141313287 & 15,1 & 179180591 & 16,1 & 175522058 & 13,5 & 212216407 & 12,5 & 2680 & 11 , & 05 & 11,7 & 47 & 14,6 \\
\hline Reval mit Baltischpor & 48895483 & 5,2 & 86235930 & 7,8 & 81116440 & 6,3 & 79388143 & 4,7 & 10977 & 4,8 & 1055 & 4,7 & 11422 & 4,3 \\
\hline Pernau ........ & 4266484 & 0,5 & 5159642 & 0,5 & 01 & 0 & 70 & 0 , & 8 & 0 & $7 \varepsilon$ & 0 , & $6 \varepsilon$ & 0,3 \\
\hline indo & 1097380 & 0 & 331 & 0 , & 2158 & 1,7 & 55359622 & 3,3 & 10656 & 4, & 122856174 & 5,5 & 93411576 & 3,9 \\
\hline$\because$ & 51954449 & 5,5 & 58995994 & 5,3 & 62346491 & 4,8 & 61127658 & 3,6 & 93358760 & 4,1 & 104254013 & 4,7 & 82206392 & 3,5 \\
\hline Ddessa. & 146407849 & 15,6 & 140232527 & 12,6 & 157840031 & 12,2 & 132748913 & 7,8 & 174511128 & 7,6 & 139597471 & 6,2 & 153079000 & 6,4 \\
\hline
\end{tabular}

Der private Grundbesitz verteilte sich vor dem Kriege wie folgt (aus Annuaire Statistique de La Latvia 1920).

Tabelle 2.

\begin{tabular}{|c|c|c|c|c|c|c|c|c|c|c|c|c|}
\hline \multirow[b]{2}{*}{ Größe in $\mathrm{Hektar}$} & \multicolumn{4}{|c|}{ In Livland } & \multicolumn{4}{|c|}{ In Kurland } & \multicolumn{4}{|c|}{ In Lettgallen ${ }^{1}$ ) } \\
\hline & $\begin{array}{l}\text { Anzahl der } \\
\text { ländlichen } \\
\text { Güter }\end{array}$ & $\%$ & $\begin{array}{l}\text { Getamtboden- } \\
\text { fläche in ha }\end{array}$ & $\%$ & $\begin{array}{c}\text { Anzahl der } \\
\text { ländlichen } \\
\text { Güter }\end{array}$ & $\%$ & $\begin{array}{l}\text { Gesamtboden- } \\
\text { fläche in ha }\end{array}$ & $\%$ & $\begin{array}{c}\text { Anzahl der } \\
\text { ländlichen } \\
\text { Güter }\end{array}$ & $\%$ & $\begin{array}{l}\text { Gesamtboden- } \\
\text { fläche in ha }\end{array}$ & $\%$ \\
\hline 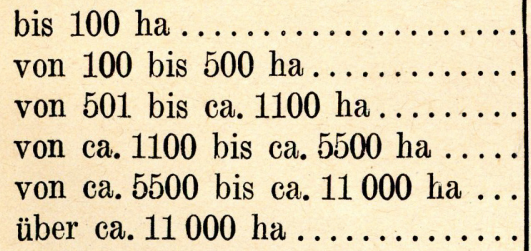 & $\begin{array}{r}12 \\
46 \\
70 \\
235 \\
41 \\
14\end{array}$ & $\begin{array}{r}2,87 \\
11,00 \\
16,75 \\
56,22 \\
9,81 \\
3,35\end{array}$ & $\begin{array}{r}555 \\
12216 \\
55269 \\
574080 \\
293955 \\
208594\end{array}$ & $\begin{array}{r}0,05 \\
1,33 \\
4,57 \\
50,15 \\
25,68 \\
18,22\end{array}$ & $\begin{array}{r}54 \\
110 \\
100 \\
187 \\
36 \\
12\end{array}$ & $\begin{array}{r}10,82 \\
22,04 \\
20,04 \\
37,48 \\
7,21 \\
2,41\end{array}$ & $\begin{array}{r}2858 \\
32175 \\
79431 \\
458079 \\
273645 \\
267220\end{array}$ & $\begin{array}{r}0,26 \\
2,70 \\
7,31 \\
40,69 \\
24,58 \\
24,45\end{array}$ & $\begin{array}{r}1433 \\
301 \\
71 \\
99 \\
7 \\
9\end{array}$ & $\begin{array}{r}74,64 \\
15,68 \\
3,70 \\
5,15 \\
0,36 \\
0,47\end{array}$ & $\begin{array}{r}43657 \\
71647 \\
54998 \\
255267 \\
55837 \\
250101\end{array}$ & $\begin{array}{r}5,97 \\
9,80 \\
7,78 \\
34,90 \\
7,36 \\
34,19\end{array}$ \\
\hline insgesamt ... & 418 & 100 & 1144669 & 100 & 499 & 100 & 1113408 & 100 & 1920 & 100 & 731507 & 100 \\
\hline
\end{tabular}

1) Zahlen für Lettgallen vom Jahre 1905. Wenn ein Besitzer mehrere Güter sein Eigen nannte, sind sie als ein Besitz aufgeführt. 
Wert der Rigaer Holzausfuhr vor dem Kriege.

Tabelle 3.

\begin{tabular}{|c|c|c|c|c|c|c|c|c|}
\hline $\begin{array}{l}\text { Jahresdurch- } \\
\text { schnitte } \\
\text { bzw. Jahre }\end{array}$ & $\begin{array}{c}\text { Groß- } \\
\text { britannien } \\
\text { Rbl. }\end{array}$ & $\begin{array}{c}\text { Holland } \\
\text { Rbl. }\end{array}$ & $\begin{array}{c}\text { Deutschland } \\
\left.\text { Rbl. }{ }^{1}\right)\end{array}$ & $\begin{array}{c}\text { Frankreich } \\
\text { Rbl: }\end{array}$ & $\begin{array}{c}\text { Belgien } \\
\text { Rbl. }\end{array}$ & $\begin{array}{c}\text { Dänemark } \\
\text { Rbl. }\end{array}$ & \begin{tabular}{|c|} 
Die übrigen \\
Länder \\
Rbl.
\end{tabular} & $\begin{array}{c}\text { Zusammen } \\
\text { Rbl. }\end{array}$ \\
\hline $1896-1900$ & 7916003 & 3189270 & 1431828 & 1638638 & 1682857 & 226817 & 118129 & 16203542 \\
\hline $1901-1905$ & 8104625 & 2862890 & 1467533 & 1181681 & 1375862 & 104154 & 88039 & 15184784 \\
\hline $1906-1910$ & 14001673 & 4531155 & 3231382 & 2801710 & 2808418 & 222511 & 375443 & 27972292 \\
\hline 1911 & 19028821 & 6968526 & 4411404 & 4305714 & 2535164 & 285822 & 502117 & 38037568 \\
\hline 1912 & 19824230 & 7390290 & 3960961 & 3920520 & 2886647 & 543830 & 939737 & 39466215 \\
\hline 1913 & 21476940 & 7233586 & 3659824 & 4178985 & 2662544 & 598714 & 643402 & 40453995 \\
\hline
\end{tabular}

1) Die tatsächliche Ausfuhr nach Deutschland war größer als in der amtlichen Statistik zum Ausdruck gebracht. Ein Teil des nach holländischen und belgischen Häfen verladenen Holzes wurde nämlich von dort nach dem westlichen Deutschland versandt. Wie groß diese Mengen waren, läßt sich nicht feststellen.

Tabelle 4

Betriebsstatistik der Rigaer Industrie ${ }^{1}$ ).

Betriebe, die weniger als 16 Arbeiter beschäftigten, sind nicht berücksichtigt.

\begin{tabular}{c|c|c|c}
\hline Jahre & $\begin{array}{c}\text { Anzahl der } \\
\text { Fabriken }\end{array}$ & $\begin{array}{c}\text { Anzahl der } \\
\text { Kessel }\end{array}$ & $\begin{array}{c}\text { Anzahl der } \\
\text { beschäftigten } \\
\text { Arbeiter }\end{array}$ \\
\hline 1901 & 278 & 629 & 47242 \\
1902 & 265 & 652 & 41909 \\
1903 & 259 & 665 & 40547 \\
1904 & 254 & 689 & 41583 \\
1905 & 254 & 721 & 43252 \\
1906 & 244 & 720 & 46166 \\
1907 & 253 & 737 & 58998 \\
1908 & 258 & 748 & 51507 \\
1909 & 269 & 749 & 52495 \\
1910 & 269 & 773 & 51640 \\
1911 & 285 & 769 & 57155 \\
1912 & 301 & 807 & 62687
\end{tabular}

1) Latvian Economist Nr. 8, 1920. Ein gewisser Zweifel an der Genauigkeit dieser Zahlen ist berechtigt, die von mir erwähnte Entwicklung spiegeln sie jedoch wieder. 
Es betrug die Einfuhr nach Riga im Jahre 1913 aus:

Tabelle 5.

\begin{tabular}{|c|c|c|c|c|c|c|c|c|c|c|c|}
\hline \multirow[b]{2}{*}{$\begin{array}{c}\text { Herkunfts- } \\
\text { land }\end{array}$} & \multirow[b]{2}{*}{$\begin{array}{l}\text { In } 1000 \\
\text { Goldrabel }\end{array}$} & \multirow{2}{*}{$\begin{array}{l}\text { In \% der } \\
\text { Gesamt- } \\
\text { einfuhr }\end{array}$} & \multicolumn{9}{|c|}{ Von der Gesamtsumme entfiel in 1000 Goldrubel auf } \\
\hline & & & $\begin{array}{l}\text { Kohle } \\
\text { Koks }\end{array}$ & Stahl & Maschinen & $\begin{array}{c}\text { Rohe } \\
\text { Baumwolle }\end{array}$ & Tee & Heringe & $\begin{array}{c}\text { Künstl. } \\
\text { Dünge- } \\
\text { mittel } \\
\end{array}$ & Rohgummi & Kopra \\
\hline Insgesamt & - & - & 14262 & 2623 & 32567 & 12200 & 4348 & 7148 & 4261 & 21148 & 3830 \\
\hline Großbritannien & 79726 & 43,2 & 12040 & 1239 & 19683 & 4309 & 4450 & 5616 & 309 & 12783 & 580 \\
\hline Deutschland & 61960 & 33,6 & Rest die & 645 & 6123 & 7812 & 80 & 266 & 1681 & 2426 & 3192 \\
\hline Dänemark & 11383 & 6,2 & übrigen & - & - & - & - & 395 & - & 2666 & - \\
\hline Holland & 10432 & 5,6 & Länder & - & - & - & - & - & 1058 & 1457 & - \\
\hline Schweden. & 8845 & 4,8 & - & 636 & 5248 & - & - & - & 437 & - & - \\
\hline
\end{tabular}

Außenhandel der Republik Lettland im Jahre 1920.

Tabelle 6 .

\begin{tabular}{|c|c|c|c|c|c|c|}
\hline \multirow[b]{2}{*}{ L and } & \multicolumn{2}{|c|}{ Einfuhr aus } & \multicolumn{2}{|c|}{ Ausfuhr nach } & \multicolumn{2}{|c|}{ Aus- u. Einfuhr zusammen } \\
\hline & In 1000 Rubeln & $\begin{array}{l}\% \text { der Ge- } \\
\text { samtsumme }\end{array}$ & In 1000 Rubeln & $\begin{array}{l}\% \text { der Ge- } \\
\text { samtsumme }\end{array}$ & In 1000 Rubeln & $\begin{array}{l}\% \text { der Ge- } \\
\text { samtsumme }\end{array}$ \\
\hline Dänemark & 442168 & 24,46 & 31062 & 2,89 & 473230 & 15,09 \\
\hline Großbritannien ..... & 425889 & 20,66 & 725985 & 67,5 & 1151874 & 36,73 \\
\hline Deutschland ............ & 382372 & 18,55 & 13426 & 1,25 & 395799 & 12,02 \\
\hline Schweden ........... & 239366 & 11,62 & 28805 & 2,68 & 268171 & 8,55 \\
\hline Norwegen.............. & 120329 & 5,84 & 206 & 0,02 & 120535 & 3,84 \\
\hline Memel-Danzig ....... & 104338 & 5,06 & 1967 & 0,19 & 106306 & 3,39 \\
\hline Holland ......... & 95021 & 4,61 & 105623 & 9,82 & 200644 & 6,40 \\
\hline Finnland ...... & 74651 & 3,62 & 9519 & 0,88 & 84170 & 2,68 \\
\hline Estland ........... & 54556 & 2,64 & 4460 & 0,42 & 59017 & 1,88 \\
\hline Frankreich.......... & 46491 & 2,26 & 68551 & 6,38 & 115042 & 3,67 \\
\hline Verein. Staaten v. Amerika. & 37192 & 1,80 & 1854 & 0,17 & 39047 & 1,24 \\
\hline Belgien ............... & 10090 & 0,49 & 74139 & 6,88 & 84229 & 2,68 \\
\hline Italien $\ldots \ldots \ldots \ldots \ldots$ & 6760 & 0,33 & 512 & 0,05 & 7273 & 0,33 \\
\hline Polen ............. & 5971 & 0,29 & 1187 & 0,11 & 7158 & 0,23 \\
\hline Litauen ........... & 5145 & 0,25 & 5940 & 0,33 & 11085 & 0,35 \\
\hline Verschiedene ............ & 10791 & 0,52 & 2244 & 0,21 & 13034 & 0,42 \\
\hline Insgesamt & $\begin{array}{r}2061131 \\
65,71 \%\end{array}$ & 100 & $\begin{array}{r}1075481 \\
34,29 \%\end{array}$ & 100 & $\begin{array}{r}3136612 \\
100 \%\end{array}$ & 100 \\
\hline
\end{tabular}


Tabelle 7.

Außenhandel der Republik Lettland im Jahre 1921.

\begin{tabular}{|c|c|c|c|c|c|c|}
\hline \multirow[b]{2}{*}{ Land } & \multicolumn{2}{|c|}{ Einfuhr aus } & \multicolumn{2}{|c|}{ Ausfuhr nach } & \multicolumn{2}{|c|}{ Ein- u. Ausfuhr zusammen } \\
\hline & $\begin{array}{l}\text { in } 1000 \\
\text { Rubeln }\end{array}$ & $\begin{array}{l}\% \text { der } \\
\text { Gesamt. } \\
\text { summe }\end{array}$ & $\begin{array}{l}\text { in } 1000 \\
\text { Rubeln }\end{array}$ & $\begin{array}{c}\% \text { der } \\
\text { Gesamt- } \\
\text { summe }\end{array}$ & $\begin{array}{l}\text { in } 1000 \\
\text { Rubeln }\end{array}$ & $\begin{array}{c}\% \text { der } \\
\text { Gesamt- } \\
\text { summe }\end{array}$ \\
\hline Deutschland & 2252121 & 48,07 & 350252 & 17,89 & 2602373 & 39,17 \\
\hline GroBbritannien . & 670038 & 14,3 & 697970 & 35,64 & 1368008 & 20,59 \\
\hline Vereinigte Staaten von Nordamerika. & 429459 & 9,17 & 21772 & 1,11 & 451231 & 6,79 \\
\hline Dänemark.................... & 365338 & 7,8 & 36837 & 1,88 & 402175 & 6,05 \\
\hline Holland ................ & 229271 & 4,89 & 100614 & 5,14 & 329885 & 4,97 \\
\hline Schweden ............ & 147244 & 3,14 & 21336 & 1,09 & 168580 & 2,54 \\
\hline Frankreich .... & 115998 & 2,48 & 101655 & 5,19 & 217653 & 3,28 \\
\hline Litauen ...... & 101929 & 2,18 & 57914 & 2,96 & 159843 & 2,41 \\
\hline Memel und Danzig. . & 92727 & 1,98 & 12640 & 0,65 & 105367 & 1,59 \\
\hline Estland .......... & 69265 & 1,48 & 29928 & 1,53 & 99193 & 1,49 \\
\hline Finnland & 55960 & 1,20 & 6983 & 0,36 & 62943 & 0,95 \\
\hline Belgien .. & 25863 & 0,55 & 316033 & 16,14 & 341896 & 5,15 \\
\hline Sowjet-Rußland & 7632 & 0,16 & 183930 & 9,38 & 191562 & 2,88 \\
\hline 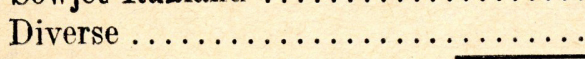 & 122048 & 2,60 & 20369 & 1,04 & 142417 & 2,14 \\
\hline Insgesamt ... & 4684893 & $100 \%$ & 1958233 & $100 \%$ & 6643126 & $100 \%$ \\
\hline
\end{tabular}




\section{Sozialwissenschailnum}

\section{Forschungen}

Herausgegeben von der

\section{Sozialwissenschaftlichen Arbeitsgemeinschaft}

Bisher sind erschienen bezw. im Druck:

Abteilung I:

Heft 1: Josef F. Feilen, Umlaufgeschwindigkeit des Geldes. Abteilung III:

Heft 1: Wilhelm Röpke, Die Arbeitsleistung im deutschen Kalibergbau unter besonderer Berücksichtigung des hannoverschen Kalibergbaues. Preis: GZ 1,5.

Heft 2: Gerhard Braun, Der Soziallohn und seine wirtschaftliche Bedeutung.

Preis: GZ 1,2.

Heft 3: Wilhelm Häfner, Motive der internationalen Sozialpolitik. Untersuchungen über ihre Entwicklung. Abteilung IV:

Preis: GZ 3.

Heft 1: Fritz von Twardowski, Das amerikanische Schifffahrtsproblem unter besonderer Berücksichtigung der Entwickelung von Schiffahrt und Schiffbau durch den Weltkrieg und die Tätigkeit des „U.S. A. Shipping Board". Preis: GZ 3.

Heft 2: Rudolph Firle, Einfluß des Weltkrieges auf Schifffahrt und Handel in der Ostsee. Preis: GZ 2. Abteilung V:

Heft 1: Robert Knauss, Die deutsche, englische und französische Kriegsfinanzierung.

Preis: GZ 5.

WeitereHeftebefinden sich in Vorbereitung

Der Preis wird errechnet durch Multiplikation der Grundzahı (GZ) mit der jew eiligen Schlüsselzahl, die in jeder Buchhandlung zu erfragen ist.

Bei Abnahme ganzer Abteilungen oder der ganzen Sammlung wird ein Subskriptionspreis berechnet.

WALTER DE GRUYTER \& CO.

VORM. G. J. GÖSCHEN'SCHE VERLAGSHANDLUNG - J. GUTTENTAG, VERLAGSBUCHHANDLUNG - GEORG REIMER - KARL J. TRUBNER VEIT \& COMP. - BERLIN UND LEIPZIG 